\title{
Resource Curse or Malthusian Trap? Evidence from Oil Discoveries and Extractions*
}

\author{
Anca M. Cotet ${ }^{\dagger}$ and Kevin K. Tsui ${ }^{\dagger}$ \\ Ball State University and Clemson University
}

December 2009

\begin{abstract}
This paper studies the effects of oil rent on development using a unique panel dataset describing worldwide oil discoveries and extractions. First, we revisit the so-called curse of oil, which contends that oil rent hinders economic development. Exploiting cross-country variations in the timing of oil discoveries and the size of initial oil in place, we find that, contrary to the oil-curse hypothesis, there is little robust evidence of a negative relationship between oil endowment and economic performance, even after controlling for initial income. Second, based on both crosscountry and panel evidence, we find a robust association between oil abundance and population growth, which might suggest a Malthusian effect which reduces the economic growth measured in per capita GDP. We find some evidence that oil abundance increases fertility. On an accounting basis, however, migration plays an even more prominent role in explaining the oilinduced population growth. Furthermore, we show that focusing on material gain may understate the welfare gain from oil abundance, because relative to non-oil countries, oil-rich countries gain more in health improvements. These results suggest that despite the positive oil effect on population growth, oil-rich countries do not suffer from the Malthusian trap, and overall oil abundance is an economic blessing rather than a curse.
\end{abstract}

JEL Classifications: O13, O15, Q32, Q56

\footnotetext{
${ }^{*}$ Support for this research was provided by the Property and Environment Research Center (PERC). Special thanks to Colin Campbell from the Association for the Study of Peak Oil and Fredrik Robelius for providing access to some of the data and institutional details of the oil industry. I also thank Terry Anderson, Dan Benjamin, Howard Bodenhorn, Bill Dougan, seminar participants at Clemson University and PERC for helpful comments and discussions. All remaining errors are ours.

${ }^{\dagger}$ Department of Economics, Ball State University. Whitinger Business Building, Room 201, 2000 W. University Ave., Muncie, IN 47306. Email: amcotet@ bsu.edu

ॠ The John E. Walker Department of Economics, Clemson University. 222 Sirrine Hall, Clemson, SC 29634. Email: ktsui@clemson.edu
} 


\section{Introduction}

One of the most enduring questions in development economics is whether successful production of extractive commodities, such as oil, promotes or hinders economic development. The staples thesis, first motivated by the experience of Canada during the 1900s, argues that natural resource booms fuel economic development. ${ }^{1}$ The idea of a "big push" provides a mechanism by which resource rents help set industrialization in motion. The disappointing growth record of some resource-rich developing countries during the past few decades, however, has inspired many economists to consider natural resource abundance as a curse for development. Understanding the impact of natural resource wealth on development has important policy implications especially in a time of concern about sustainable economic development and energy security. ${ }^{2}$

The association between economic development and oil wealth is controversial. The cross-country empirical research on the so-called "resource curse" began with Sachs and Warner's (1995) widely-cited study, which documented a negative statistical relationship between natural resource dependence, measured by exports of natural resources as a fraction of GDP, and economic growth. ${ }^{3}$ However, resource dependence (or comparative advantage in resource products) is not the same as resource abundance (Brunnschweiler and Bulte, 2008; Wright and Czelusta, 2004). With improved measurement of resource abundance, recent studies find that natural resource wealth tends to positively affect economic growth (Alexeev and Conrad, 2009a; Brunnschweiler and Bulte, 2008; Lederman and Maloney, 2008).

Like many other cross-sectional regression analyses, these cross-country resource-curse studies suffer from various problems of omitted variable and endogeneity biases as well as

\footnotetext{
${ }^{1}$ In a classical paper, however, Chambers and Gordon (1966) challenge the staple thesis and argue that the positive impact of resource booms on economic growth is exaggerated. Interestingly, they conjectured that one possible reason is that the economic benefit from resource booms will be at least partially absorbed by the resource-boomsinduced population growth. In the case of the wheat boom in Canada, they wrote, "For one basic reason the conclusion so far reached ... unquestionably exaggerates the effects of the staple. This is because the model produces no growth in population due to the wheat boom, and this in turn is due, among other things, to the assumption that population only migrates for wages. No part of the increase in rent would go to new immigrants, but would be captured in its entirety by individuals previously resident in Canada."

${ }^{2}$ For example, the World Bank's 2003 World Development Report found that unsustained growth is closely associated with point-source resources, and the resource curse doctrine forms the rationale behind many development programs such as the World Bank's Chad-Cameroon Petroleum Development and Pipeline Project.

${ }^{3}$ Sala-i-Martin (1997) even concludes that natural resource dependence is one of the ten most robust variables in empirical studies on economic growth, although Sala-i-Martin et al. (2004) find that the fraction of GDP in mining has a robust and positive relationship with growth. van der Ploeg (2006) provides some useful overviews of the resource curse literature. Papyrakis and Gerlagh (2007) provide similar evidence using U.S.-state-level data.
} 
measurement error, and hence the reliability of the evidence has been seriously questioned. First, countries with insecure ownership may be less effective in oil exploration and extraction, whereas leaders in a politically unstable environment (e.g. civil war) may over-extract relative to the efficient extraction path because they have higher discount rates. Therefore, cross-country evidence based on current oil reserves or production to proxy for oil abundance is likely to be subject to omitted variable as well as endogeneity biases. Second, without information on the timing of oil discovery, controlling for the "initial" level of income may introduce additional bias because the initial level of income is endogenous to oil wealth when it is measured after oil extraction took place (Alexeev and Conrad, 2009a). Third, while some of these recent studies mentioned above correctly point out the endogeneity problem introduced when the size of natural resource is deflated by GDP, because the denominator explicitly measures the magnitude of other activities in the economy, their new measure of resource abundance, resource stocks per capita, suffers from a similar endogeneity problem because population, as we argue in this paper, is also endogenous to oil abundance.

"Dutch disease" (i.e. an economic crowding out of increasing-return activities) 4 and rent seeking (i.e. a political crowding out of productive activities) ${ }^{5}$ are the two leading explanations for the resource curse; none of the previous studies considers the possibility of a Malthusian effect - a positive effect of the standard of living on the population growth, which eventually might lead to a negative feedback from the size of population to the standard of living. ${ }^{6}$ The lack of empirical analysis on the Malthusian mechanism is surprising given the high fertility and low female labor force participation rates among the oil-rich Arab countries, as well as their adoption of pro-natalist policies following the oil boom in the early 1970s (e.g. Winckler, 2009). ${ }^{7}$ A better understanding of the demographic transition in oil-rich countries is also useful in evaluating the growth prospect of these countries according to the unified growth theory (Galor, 2005).

\footnotetext{
${ }^{4}$ See Sachs and Warners (1999) and Torvik (2001).

${ }^{5}$ See Lane, and Tornell (1996), Robinson, Torvik, and Verdier, (2006), and Torvik, (2002).

${ }^{6}$ An interesting recent exception is Weil and Wilde (2009), which does not address the resource curse problem directly but asks the general question: How Relevant is Malthus for Economic Development Today?

${ }^{7}$ One policy adopted by the Saudi government, partly as a result of the disappointingly small numbers of Saudi nationals reported in the 1974 population census, was that contraceptives were pronounced to be contrary to the teaching of Islam, and their import was banned in the spring of 1975. To encourage early marriage, since the beginning of the 1980s, the Kuwaiti government has granted a marriage allowance of 2,000 Kuwaiti Dinar (KD) to nationals marrying for the first time, with an additional 1,000 KD offered as a soft loan.
} 
This paper uses data on worldwide discoveries and production of oil to provide new evidence of the effect of oil wealth on development. ${ }^{8}$ We first re-examine the resource-curse hypothesis in a cross-sectional context - after correcting for the possible biases because of mismeasurement of initial income and omitted variables, which affect both current oil abundance and development. We assemble data on the timing of oil discoveries and the size of initial oil endowment. Knowledge of the timing of oil discoveries helps to solve the endogeneity problem by identifying the relevant growth period so that we can make a more accurate before-and-after comparison. Our data confirm the criticism that controlling for initial level of income (usually measured at year 1970) creates an endogeneity problem because global oil discovery peaked in the early 1960s, with many oil-rich Middle East countries having a peak discovery year prior to 1950. On the other hand, since the formation and accumulation of oil are determined by geology, cross-country variation in initial oil endowment (before any extraction) provides an exogenous variation in oil abundance. Exploiting variation in initial oil endowments attributable to geography as well as differences in the timing of oil discovery, our analysis compares changes in GDP per capita before and after oil discovery in countries abundant in oil with changes in otherwise similar countries with small or no oil endowments.

Growth in GDP per capita can be driven by changes in total GDP, changes in population, or a combination of both. To the extent that children are normal goods, we might expect a resource boom to induce higher fertility rates among oil-rich countries (Black et al., 2009). Using our before-after research design, we can decompose the source of economic growth into its intensive and extensive components, so that we can evaluate to what extent the resource curse can be explained by a Malthusian trap. For instance, even in the absence of crowding out and oil rent has a multiplier effect on total GDP, part of the gain in GDP per capita can be absorbed by the induced population growth. Furthermore, we examine if the oil-induced difference in population growth is driven by differences in birth, death, or migration rates. Finally, while GDP per capita provides one useful measure of the quality of life, overall economic welfare depends on both the quality and the quantity of life, represented by longevity. It is shown that in addition to material gain, many dimensions of health were substantially improved throughout the twentieth century (Becker, Philipson, and Soares, 2005). Focusing on material gain may

\footnotetext{
${ }^{8}$ We focus on the case of oil because oil has become the most important extractive commodity since the turn of the middle of the twentieth century. Moreover, the high-quality data exist in the case of oil.
} 
therefore understate the welfare gain from oil abundance. Indeed, some Middle East scholars argue that oil revenues enable many Arab governments to establish welfare states that benefit the population with the provision of subsidized health care and education (Fargues, 2003). ${ }^{9}$ To conduct a more comprehensive assessment of the welfare implication of oil abundance, we also investigate if oil-rich countries gain more in life expectancy and infant mortality reduction.

Contrary to the resource-curse hypothesis, our before-after research design shows that there is little robust evidence of a negative relationship between oil endowment and economic growth (measured by growth in GDP per capita) even after controlling for initial income. Indeed, when extreme outliers are dropped, we find that oil discovery has a significant positive effect on economic growth. The oil effect on total GDP growth is even larger, because oil discovery also leads to higher population growth. In particular, discovering 6,000 barrels of oil per capita (the size of an average large-oil country, which is approximately the initial endowment of Trinidad and Tobago) increases the average annual population growth rate by almost 0.17 percentage points over the three decades after the discovery. Unlike the oil impact on economic growth, this oil effect on population growth does not depend on whether outliers are included or excluded from the sample. While we do find some evidence on the oil-induced Malthusian effect through higher fertility, on an accounting basis, migration plays an even more prominent role in explaining the population growth. Finally, we show that focusing on material gain may overstate any negative Malthusian effect on overall welfare, because there is some evidence that oil-rich countries gain more in longevity and suffer less from infant mortality.

While cross-country regressions with exogenous variation in the variable of interest are useful in identifying causal effects in the long run, one important drawback of them is the potential problem of omitted variable bias because of unobserved heterogeneity. We argue that in the case of oil and development, cross-country estimates tend to overstate the oil impact on economic growth and understate the impact on population growth when these omitted factors,

\footnotetext{
${ }^{9}$ In an interesting early article, Benjamin and Kochin (1982) anticipate the Malthusian effect because of the optimal government's response to windfalls. According to Benjamin and Kochin, a government which maximizes the wellbeing of its constituents will maximize the rents of the immobile factor. The efficient response to the receipt of a windfall is to distribute the windfall to the owners of immobile resources via reduction in their taxes. For instance, in 1980 the Alaska State Legislature passed a law granting residents cash dividends from current and future oil revenue, where the criterion for receipt of the distribution is based on the length of prior residence in the state. Such a policy provides incentive for higher fertility from local residents. Similar distribution schemes are observed in many Middle East oil-rich countries.
} 
such as favorable institutional structure, encourage oil exploitation and promote economic development. Focusing on cross-sectional variation also leaves the time-series variation in oil price unexploited. Our second strategy is to use panel methods to exploit within-country variation in oil rent so that we can control for possible country-specific omitted factors that do not change over time. In other words, we ask whether a country is more likely to have (relatively) slower growth as it receives more oil rent. Our results based on panel evidence are broadly consistent with the results from cross-country estimation: oil rent is not an economic curse, although our estimates do not support the Big-Push argument either, and the positive effect on population growth absorbs a fraction of the oil-induced growth in total income. Overall, however, citizens from oil-rich countries at least gain by more health improvements.

The paper proceeds as follows. Section 2 begins with a discussion of Alexeev and Conrad's critique of the existing resource curse literature. We highlight the tradeoff between including and excluding a proxy for initial income, and we argue that their criticism may also apply to their study, especially when population is endogenous. We then describe how our data can address these econometric problems. Section 3 presents the basic results based on a crosscountry before-after comparison. Section 4 extends our analysis in a panel framework. Section 5 provides sensitivity checks. Section 6 discusses the interpretation of our findings and concludes.

\section{The Elusive Curse of Oil}

We first review in this section some recent criticisms of previous empirical studies on the resource curse problem (Alexeev and Conrad, 2009a; Brunnschweiler and Bulte, 2008). Among these, Alexeev and Conrad's main criticism can be interpreted as a problem of the tradeoff between errors of omission and measurement first studied by McCallum (1972). After explaining why their empirical strategy may also suffer from similar endogeneity and measurement problems, we describe how our data can help address them.

\subsection{Tradeoff Between Including and Excluding Proxy for Initial Income}

Alexeev and Conrad (2009a) identify several econometric problems from the resource curse literature. First, they argue that when controlling for the initial level of income in their regressions, these earlier studies, which compare growth rates across countries over a specific 
period of time, create an endogeneity problem because the initial income is usually measured after the first commercial exploitation took place. ${ }^{10}$

To better understand Alexeev and Conrad's major critique and their solution to the problem, it is useful to reinterpret it as a general econometrics problem: Is it better for the estimation of the coefficient of interest (the oil coefficient in our case) to include other variables (initial level of income in our case) measured with error? In an early attempt to address this problem, McCallum (1972) shows that, under some plausible assumptions, the asymptotic bias will be smaller if the proxy is used than if the missing variable is simply omitted. Accordingly, even if early income data are unreliable, the "kitchen sink approach" is justified. In our case, if oil endowment and initial income are positively correlated, the oil coefficient will be subject to an upward bias when initial income is omitted, and introducing a proxy for initial income will reduce this upward bias. Estimates from regressions that omit the initial income variable may be biased upward if wealthier countries are more successful in oil exploration. Nonetheless, Griliches (1977) argues that including a proxy can easily introduce a downward bias to the coefficient of interest when the variable of interest is also subject to errors of measurement, because the bias from this measurement error will be magnified as more variables are included in the regression. Moreover, even in the absence of measurement errors, caution should be taken when including any control variable which is endogenous to the variable of interest. ${ }^{11}$ These considerations suggest that, especially when oil abundance is measured with error, controlling for the initial level of income may bias the oil coefficient downward, which is the main concern raised by Alexeev and Conrad.

\subsection{Entire Growth Period vs. Relevant Growth Period}

The main issue, according to Alexeev and Conrad, is the effect of resource endowment on the economic growth over the entire period of discovery and commercial use of the resource and beyond. Because of concern over the reliability of early income data, and more importantly, because of the lack of detailed information on the timing of discoveries, their approach is to

\footnotetext{
${ }^{10}$ In the resource curse literature, growth rates are usually measured as an average rate for a 25-30 year period starting in 1965 or in 1970.

${ }^{11}$ In labor economics, a well-known example is to control for test scores as a proxy for ability when estimating the return to education.
} 
measure long-term growth via GDP per capita levels measured in the year 2000 rather than to calculate growth rates over a given period of time.

To illustrate, Figure 1 presents the time series of the average GDP per capita for three groups of countries, classified according to their oil reserves per capita at the year 1980. Over the sample period 1960-2000, all country groups were growing steadily, except the group with the largest oil reserves during the 1980s. The negative economic growth experienced by these oilrich countries for more than a decade is the main driving force behind the curse-of-oil result. Alexeev and Conrad's observation is simple: larger oil endowments are associated with higher level of current per capita income, although their growth rates may be relatively slow over the sample period. Based on their analysis, they conclude that oil-rich countries experienced high growth rates in the early stages of extraction and perhaps slower rates when the oil deposits mature, but so far oil resources have enhanced rather than inhibited long-term growth. Indeed, according to our figure, countries with more oil are always wealthier throughout the sample period. Moreover, countries with small oil reserves were growing faster than countries with no oil, although one must be cautious in drawing causal inference from aggregate time series data.

By omitting initial income, Alexeev and Conrad are essentially asking the question "Are countries with larger oil endowments richer than those with less or no oil in the year 2000?" From a theoretical perspective, unlike the cross-country growth regression framework which can be derived from the neoclassical growth model, level regressions are less easily traceable to a single theoretical model (see Barro (1998) for an excellent survey of the cross-country growth literature). More importantly, if the goal is to measure the long-term growth impact of oil over the "entire" period, why choose year 2000, instead of, say, 1970 or 2030, to measure the "final" level of income? ${ }^{12}$ Obviously, as of today, data on year 2030 do not exist. The problem is, as long as a country is producing oil, it is impossible to estimate the oil impact on growth for the entire period. Choosing an arbitrary year to measure the final level of income, which in practice is determined by the year of the research being conducted, introduces another bias because

\footnotetext{
${ }^{12}$ There is an empirical literature on cross-country income accounting, which aimed at accounting for variation in the level of income per capita rather than in its growth rate (e.g. Hall and Jones (1999)). However, given that the question from the resource curse literature is whether natural resource promotes or hinders growth and development, the relevant regression is to control for initial income. Another related reason for the inclusion of initial income as a control variable is that of the growth effect of oil depends on the initial income. In other words, our specification allows for the possibility that the growth effect of oil being a function of initial income.
} 
different countries with different size of oil endowment discovered oil at different years and presumably have different relevant "entire period of discovery and commercial use of the resource and beyond."13

\subsection{Endogeneity of Measures of Oil Abundance}

Another criticism from both Alexeev and Conrad (2009a) and Brunnschweiler and Bulte (2008) is that previous studies use oil dependency, measured by the share of oil output (or exports) in GDP as the independent variable of interest. Since the research question is about the effect of natural resource on GDP, using oil dependence introduces an endogeneity bias similar to a division bias which biases the estimate downward. In their main specification, they use measures of current natural resources expressed per capita. ${ }^{14}$

However, using current natural resources per capita as an independent variable in crosscountry analysis creates two problems. First, as mentioned above, because different countries discovered oil at different years, comparing cross-sectional oil reserves at a given point in time may understate the extent of oil abundance for those who discovered and started producing oil earlier. ${ }^{15}$ Second, and more importantly, the main point of our paper is that population is endogenous to oil abundance, and hence their argument applies to both current GDP and population. In particular, if oil has a positive effect on population growth, normalizing oil by current population can create an upward bias in estimating the oil impact on economic growth.

To see this, for each cross section from 1970-2000 Table 1 presents the regression estimates of the effect of oil abundance on (log of) GDP per capita. Following Alexeev and Conrad (2009a), we consider a highly parsimonious specification which controls only for a few geographic and demographic variables including absolute value of latitude, dummy variables for two different geographical regions (namely, East Asia/ Pacific and sub-Saharan Africa), ethnic

\footnotetext{
${ }^{13}$ For example, according to our oil data (see the details below), the estimated peak year of production for Kazakhstan is 2030. Measuring income for Kazakhstan at year 2000 will therefore miss a large fraction of the oil impact on economic growth because it is estimated that the oil production will increase over the next 20 years. On the other hand, measuring income on year 1970 will overstate the oil impact on growth for countries like Norway, which has peak discovery year 1979.

${ }^{14}$ More precisely, Alexeev and Conrad (2009a) use hydrocarbon deposits per capita in year 1993.

${ }^{15}$ For instance, although the United States and Saudi Arabia have similar amount of oil endowment, according to our data, Saudi Arabia's current oil reserves is 6 times more than the reserves of the United States, because the United States started extracting oil almost 8 decades before Saudi Arabia did and as a swing producer for OPEC Saudi Arabia has been producing below its full capacity.
} 
and religious fractionalization, and the fraction of Muslim population. In columns (1) and (2), oil abundance is measured by current value of oil reserves normalized by GDP. Consistent with the resource curse hypothesis, for the year 2000 cross section, column (1) shows that oil is strongly negatively correlated with economic growth over the period 1960-2000. Once dropping the initial per capita income as a regressor, however, column (2) shows that this correlation disappears (with a positive, though statistically insignificant, elasticity of 0.0196). Alexeev and Conrad prefer to use measures of natural resources that are not expressed as shares of GDP, because they are interested precisely in the effect of natural resources on GDP. Replacing the measure of oil by current oil reserves per capita, the oil coefficient becomes positive and strongly significant (column (3)). The implied elasticity is doubled (0.0394), which is consistent with their argument that deflating oil by GDP tends to introduce a downward bias. We agree with Alexeev and Conrad's logic because current GDP is endogenous to oil, but what they are interested in is not just GDP but the ratio of GDP and population, and hence normalizing by current population can be equally problematic if oil affects population growth. In column (4), when oil abundance is measured by current reserves divided by population in 1960, the size of the estimated coefficient shrinks, with the implied elasticity becomes almost $30 \%$ smaller (0.0298). Measuring oil abundance by oil reserves per capita in 1960, we obtain a slightly larger estimate, with the implied elasticity 0.0269 which is again much smaller than the one implied by column (3). Because lagged oil reserves (rather than current reserves) is a better predictor of current production, this smaller estimate suggests that using current reserves per capita tends to overstate the impact of oil on economic growth.

The rest of the table presents results from different cross sections. A similar pattern is observed across specifications. More importantly, there is also wide variability in the magnitude of the estimated effects of oil across cross sections for a given specification. For example, even controlling for initial income in column (1), there is no oil curse from both the 1970 and 1980 cross sections.

\subsection{Data on the Timing of Oil Discoveries and the Size of Initial Oil in Place}

To identify the relevant (not the entire) growth period, we assemble data on the timing of discoveries as well as the size of ultimate oil endowment, so that we can compare income before and after oil discoveries. The oil endowment and discovery data are obtained from Dr. Colin 
Campbell at the Association for the Study of Peak Oil (ASPO), a non-profit organization that is devoted to gathering industrial data to study the dates and impact of the peak and decline of world oil. While oil exploration and extraction activities extend over time, our data suggest that a country's major discoveries are usually concentrated in a few years, known as the peak discovery period. Knowledge about the timing of oil discoveries is important because it helps to solve the endogeneity problem by identifying when the initial income should be measured. The ASPO dataset covers most oil countries. For the rest of the world, oil endowment is either insignificant or nil. The oil endowment of these countries is imputed by adding cumulative production to current reserves, both of which are identified from public data. The peak discovery date is imputed using the regional peak year given by the ASPO dataset. ${ }^{16}$

The dataset also provides an estimate of the total oil initially in place for each main oilproducing country. The amount is estimated most recently by geologists, using statistical techniques involving size distributions and geological habitats. Because oil is a natural resource, the size of a deposit before any extraction is exogenous. ${ }^{17}$ More importantly, unlike oil reserves at a given year, our measure does not depend on the success of exploration and the rate of depletion, which might be affected by unobserved factors which also determine development. To check the robustness of the ASPO's estimate of oil endowment, in section 5, we present results based on another independent estimate of oil endowment from the US Geological Survey.

\section{Oil and Development: Revisiting the Cross-Country Evidence}

In this section, we revisit the cross-country evidence with two aims. First, we examine whether identifying the relevant growth period through the timing of oil discoveries and using exogenous measures of oil abundance affect the results of the long-term growth impact of oil, and we also explore if the oil-growth relationship varies across time horizons. Second, we decompose the oilinduced growth into extensive growth and intensive growth so that we can understand if oil-rich countries suffer negative economic effects from overpopulation. In addition, we further decompose the oil-induced population growth into crude birth, crude death, and migration rates,

\footnotetext{
${ }^{16}$ We provide robustness check when focusing on oil-producing countries only in section 5 .

${ }^{17}$ More details on the data sources are provided in the Data Appendix. Tsui (forthcoming) also provides a detailed description of the oil dataset.
} 
and we also consider the effects on other related health outcomes, including infant mortality and life expectancy.

\subsection{Before-After Comparison Using Exogenous Measures of Oil Abundance}

We begin by organizing the raw data in various ways to present some initial evidence of the long-term impact of oil abundance on development. Before we report our results, we note that Easterly (2004) observes that many results from cross-country growth regressions are driven by outliers. As a point-source natural resource, the distribution of oil endowment is highly skewed. We identify an extreme outlier from our sample (United Arab Emirates), which we think is driven mostly by measurement error (see the appendix for the details, including some robustness checks). In what follows, we report the results based on the sample excluding this outlier.

Figures 2 and 3 provide an overview of trends of the average per capita GDP and population for three groups of countries, classified according to their initial oil endowment per capita. Unlike Figure 1, these countries are sorted according to their year of peak oil discovery, so that these trends illustrate changes in income and population before and after oil discovery. The trends from Figure 2 are similar to Figure 1, with an important exception that from the two to the three decades after the peak discovery year, which is around 1960 globally, the trend is almost flat rather than negatively sloped. Given that the large-oil countries do not seem to grow slower than the no-oil countries, and the small-oil countries seem to grow faster than the no-oil countries, it is hard to see any obvious curse of oil from this figure. Figure 3 depicts the pattern in population trends: population diverges, with population growing faster in oil-rich countries.

Descriptive statistics are summarized in Table 2. Countries are again classified into three groups, according to their oil abundance defined as above. Initial GDP per capita is measured as the log of average GDP per capita over the decade before the peak year. The dependent variable annual average growth rate of GDP per capita is the difference between this variable and the log of average GDP per capita over the third decade after the peak year and then divided by the number of years between them. ${ }^{18}$ Other dependent variables, annual average growth rate of total GDP and annual average growth rate of population, are defined in a similar way.

\footnotetext{
${ }^{18}$ Growth under different time horizons will be considered in the regression analysis below.
} 
Growth in total GDP is monotonically increasing in oil abundance, which is inconsistent with the notion of over-dissipation of rents. Population in countries with the largest oil endowment grows faster than countries with smaller oil endowment. As such, in terms of per capita GDP growth, countries with the largest oil endowment do not grow faster than countries with smaller oil endowment, although countries with no oil grow systematically more slow than oil-countries. Although these differences are not statistically significant in the raw data, they suggest that, (1) oil abundance is not likely to be an economic curse, and (2) population grows faster in countries with sufficiently large oil endowment.

The rest of the table shows that the sample of countries with different oil endowments is balanced across a variety of variables, suggesting the distribution of initial oil endowment is more or less random. While the distribution of oil endowment is highly skewed, there is no systematic difference in the peak discovery year, religious fractionalization, and percentage of Muslim across countries groups. Although there are significant differences in initial total GDP, initial population, ethnic fractionalization, and latitude across countries groups, none of these differences is monotonic in oil abundance. The only systematic and significant difference is initial GDP per capita: oil abundance and initial income are positively correlated. To the extent that initial income is contaminated by oil rent because of measurement error, we tend to underestimate the positive economic effect of oil abundance. In other words, if we do not find a robust negative association between oil abundance and economic growth even after controlling for initial income, we can comfortably reject the oil-curse hypothesis.

To estimates the long-term impact of oil discovery on growth, we consider the following simple, long-difference, before-and-after empirical strategy:

$$
\text { INCOME_GROWTH }{ }_{i}=\beta_{1}+\beta_{2} \text { INITIAL_INCOME } i+\beta_{3} \mathrm{OIL}_{\mathrm{i}}+\mathrm{X}_{\mathrm{i}}^{\prime} \beta_{4}+\varepsilon_{\mathrm{i}} \text {, }
$$

where the variables INCOME_GROWTH ${ }_{i}$, INITIAL_INCOME $_{i}$, and OIL $_{i}$, are defined as above. Following the literature, $\mathrm{X}_{\mathrm{i}}^{\prime}$ is a set of control variables which includes absolute value of latitude, dummies for East Asia (including Pacific) and sub-Saharan African countries, and ethnic and religious fractionalization. ${ }^{19}$ We also control for the fraction of Muslim population because many

\footnotetext{
${ }^{19}$ Institutional quality will be considered in section 5 . We do not control for institutional quality in our main
} specification, as in Alexeev and Conrad (2009a) and Brunnschweiler and Bulte (2008), because data on these 
oil-rich countries are Muslim countries and the pro-natalist teaching in Islam is sometimes said to be responsible for high fertility rates in many Muslim nations. Since countries may have different peak discovery years, we also include time (decade, in particular) fixed effects in our regressions. Section 5 shows that our results are robust to adding additional controls. $\varepsilon_{\mathrm{i}}$ is an error term capturing all other omitted factors. As in any other cross-country regressions, the key identification assumption is that conditioning on observables the error term is mean zero. The regression equations for total GDP growth and population growth are defined in a similar way.

Table 3 presents our main results from the before-after comparison with different time horizons. For each time horizon, the estimated oil coefficients from two specifications are reported, one only with initial income (or initial population in the population growth regression) and time fixed effects as controls and one with the full set of controls. Focusing first on the effect on total GDP growth from the first row, it shows that larger oil discovery leads to significantly positive and sustainable extensive growth measured in total GDP, which refutes the possibility of over-dissipation of rents. For instance, over the three-decade horizon, the point estimate of 1.121 (with standard error 0.285 , and hence significant at the $1 \%$ level) implies that discovering 6,000 barrels of oil per capita (the size of an average oil-rich country, which is approximately the initial endowment of Trinidad and Tobago) increases the annual average total GDP growth rate by almost 0.7 percentage points over the three decades after the discovery.

The second row of Table 3 shows that larger oil discovery also leads to significantly higher population growth. In particular, discovering 6,000 barrels of oil per capita increases the annual average population growth rate by almost 0.2 percentage points over the three decades after the discovery. Since the effect on population growth is dominated by the impact on extensive growth, oil-rich countries indeed also gain from intensive growth, measured in GDP per capita - discovering 6,000 barrels of oil per capita increases the annual average GDP per capita rate by more than 0.5 percentage points over the three decades after the discovery.

Our estimates of the development impact of oil abundance are quite precise, and the effects persist over different time horizons. Moreover, in most cases, the effects are significant with and without including the control variables. Figures 4 and 5 depict our regression results

measures are not available until 1996, and hence to the extent that institution is endogenous to oil abundance, Alexeev and Conrad's main critique applies. 
using partial residual plots. Casual observation suggests that our results are not driven by a few outliers, which is always a concern in cross-country regression analysis. We show in section 5 that our estimated oil impacts are robust to eliminating some of the most oil-rich countries.

\subsection{Sources of the Oil-Induced Population Growth}

We have found strong cross-country evidence that oil encourages population growth, but how exactly? According to the Malthusian model, fertility rises and death rates fall when per capita income exceeds the equilibrium level. In this subsection, we consider different sources of the oilinduced population growth by investigating the impact of oil abundance on the number of births, deaths, and net migration. Because of the lack of pre-discovery data on these variables, we conduct our analysis under the standard cross-country growth framework, using initial oil reserves per capita to measure oil abundance. To check the robustness of our estimates, we run the regressions over different periods as well as time horizons.

The results are reported in Table 4. The dependent variable in the first column is annual average population growth over the relevant period. Next, the dependent variable average births is computed as the average total number of births divided by initial population over the sample period. Note that our measure is different from the average of standard birth rates over the sample period. First, to construct a consistent decomposition of population growth into births, deaths and net migration over a certain period, we divide all the variables by the same initial population. Second, because oil abundance can potentially affect population through deaths and net migration, the impact on standard birth rates can be confounded with other changes in population. Expatriates form the majority of many oil-rich Arab states, with large percentage of the expatriates are male workers in the oil sector. For example, in Qatar, population has an unusual sex distribution consisting of almost twice as many males as females, and the imbalance is the most prominent in the 15-65 age group and among the new migrants. ${ }^{20}$ Deflating births by current population will therefore understate the impact on fertility because of the skewed current

\footnotetext{
${ }^{20}$ According to the statistics from the United Nations, in 2000, Qatar's gender imbalance is the second highest among any nation in the world followed by other oil-rich Arab states Kuwait, Bahrain, Oman, and Saudi Arabia. Qatar has a heavily skewed sex ratio of 1.85 males per female. UAE, another oil-rich Arab state, has an even more skewed sex ratio of 2.08 males per female. The United Nations also report the sex ratio of international migrants in 2005. The figures are respectively 2.56 and 2.86 males per female in UAE and Qatar. We drop UAE in our baseline sample because it is identified as an extreme outlier in our cross-country regressions (see Appendix B). On the other hand, in other Arab countries with relatively poor oil endowment such as Jordan and Syria, the overall sex ratios are only 1.07 and 1.01 male per female respectively.
} 
sex ratio induced by oil abundance. ${ }^{21}$ The dependent variables average deaths and average net migration are calculated in a similar way. Finally, to provide a more direct test of the Malthusian mechanism, column (5) also reports the estimates using total fertility rate as a dependent variable. For consistency, all the data on the dependent variables, including the population data, are taken from the World Development Indicator. All regressions are run with the full set of controls, including initial level of log population, log GDP per capita, democracy, age structure of population, and other geographic and demographic controls from the previous regressions.

Column (1) shows that the oil effect on population growth holds over different periods as well as time horizons, with the effect the weakest during the 1980-2000 period. The effect of oil abundance on births is summarized in column (2). Our results are broadly consistent with the conjecture that children are normal goods. Oil-rich countries have significantly more births in all periods, although the effect becomes weaker in magnitude over time. For example, over the 1960-1980 period, a discovery of 1,000 barrels of oil reserves per capita (the average reserves per capita in 1960) increases the average birth rate by about 0.5 children per 1,000 people per year. On the other hand, column (3) shows that there is no robust relationship between oil abundance and the number of deaths.

While the traditional Malthusian analysis usually pays little attention to migration, column (4) shows that net migration is indeed always a more important driving force of population growth compared with births. In particular, over the 1960-1980 period, the oil effect on net migration is almost four times larger than the impact on births. The relative importance of migration is even more prominent in other periods. Since a large fraction of these migrates are male workers in the oil industry, such a finding justifies our measure of birth rate which deflates the number of births by initial instead of current population.

Because of the large influx of migrants, even though the majority of them are male workers and some of them are temporary migrants, there is a concern of an upward bias using our measure birth rates in column (2), when part of the increase in births may come from the children from these migrant workers. Similar results are obtained in all time periods and horizons when we deflate births by current female population. For example, using births as a fraction of

\footnotetext{
${ }^{21}$ Note that in the absence of disaggregated demographic data, we cannot disentangle the effect on births among nationals and foreigners.
} 
female population averaged over the sample period as a dependent variable, the estimated coefficients are 0.479 and 0.208 respectively over the 1960-1980 and 1970-1990 periods. $^{22}$ Alternatively, using fertility rate as a dependent variable, column (5) indicates that oil abundance has a positive impact on fertility in all periods and they are statistically significant except over the 1970-1990 period, which experienced a decade of oil bust in the 1980s. Although most of these estimates are highly statistically significant, the average magnitude of the impact is rather small. Over the period 1960-1980, for instance, a discovery of 1,000 barrels of oil reserves per capita increases the average fertility rate by only 0.04 children. However, since the distribution of oil reserves is extremely uneven, the impact on fertility for the richest oil country (with almost 54,000 barrels per capita in our sample) is 2 more children, which is significantly larger. ${ }^{23}$

Overall, our cross-country evidence based on different measures of birth rates and fertility suggests that oil abundance is positively associated with higher fertility rate, although migration appears to play a more important role in explaining the oil-induced population growth. These findings suggest that despite the high fertility rate among oil-rich countries, the classical Malthusian mechanism is not sufficient to explain the growth pattern in these countries.

\subsection{Resource Curse or Malthusian Trap?}

One important implication from the Malthusian model is that holding the function generating population growth constant, increases in the stock of resources will eventually result in more people but not a higher standard of living. However, Becker, Philipson, and Soares (2005) show that improvement in health outcomes has been significant throughout the post-World War II period, especially among developing countries, and hence focusing on material gain may

\footnotetext{
${ }^{22}$ All these estimates from different periods and time horizons are significant at the $1 \%$ level. Indeed, using average standard birth rate as a dependent variable, the estimated oil coefficients are also positive and significant for the 1960-1980, 1960-1990, and the 1960-2000 periods, although the magnitude of the effect is smaller. For example, using the 1960-1980 sample, the estimated coefficient is 0.201 (standard error=0.041), which implies a discovery of 1,000 barrels of oil reserves per capita increases the average birth rate by about 0.2 children per 1,000 people per year. The magnitude of the effect is smaller because the number of births in this case is deflated by current population which consists of a disproportional fraction of male migrant workers.

${ }^{23}$ It should be also noted that our estimates using fertility can be biased downward if single young women migrate to earn money rather than start a family. Remittances have always formed a significant part of international resource flows among the Arab countries in the Middle East. The pattern of the remittance flow from oil-exporting countries (e.g. Saudi Arabia) to labor-exporting countries (e.g. Egypt) suggests that many of the migrants have their family in their home countries. Mohammed (2003) documents that in many oil-rich Gulf Arab States such as Kuwait and Oman, the proportion of dependents amongst the non-national population is relatively small, whereas female nationals have not been joining the workforce until recently.
} 
understate the improvement in living standard even though there is no apparent economic growth. On the other hand, Besley and Kudamatsu (2006) find that citizens are healthier under democracy, and in particular the democracy effect on health is the strongest for the decades of the 1960 s and 1970 s because democracies were quicker to adopt mortality reducing technologies. Since numerous recent studies also show that oil hinders democracy (e.g. Aslaksen, forthcoming; Tsui, forthcoming), one might expect citizens from oil-rich countries gain less in health outcomes, especially during the 1960s and 1970s because of the indirect institutional effect. Indeed, Besley and Kudamatsu find that mineral exporting countries have lower life expectancy. When this true, oil can still be a curse even if oil-rich countries do not suffer from slower economic growth. ${ }^{24}$

Following Besley and Kudamatsu (2006), we consider two main health outcomes: infant mortality and life expectancy. ${ }^{25}$ Table 5 reports the reduction in infant mortality and gain in life expectancy over different periods, using data from the World Bank. In sharp contrast to Besley and Kudamatsu's findings, row (1) shows that oil abundance has a negative impact on infant mortality and a positive impact on life expectancy during the 1960s and 1970s, although the effects are insignificant over the 1970-1990 period from row (2). Indeed, using data from the United Nations, which have a few more observations, we find even more significant effects over the 1960-1980 period. In particular, the point estimate for the infant mortality regression is 0.599 (standard error $=0.233$, and hence significant at the $1 \%$ level), and the point estimate of the life expectancy is 2.127 (standard error $=0.874$, and hence significant at the $5 \%$ level). Row (3), however, shows that oil-rich countries suffered from higher infant mortality and lower life expectancy over the 1980-2000 period. ${ }^{26}$ According to row (4), overall the full sample period 1960-2000, there is no evidence that oil-rich countries gain less in health improvements.

The results from the early period provide suggestive evidence that oil-rich countries gain more in health improvements earlier instead of later, although the health gap has been closing

\footnotetext{
${ }^{24}$ After completing the first draft of this paper, we found that Alexeev and Conrad (2009b) study a similar problem under a cross-country framework. Using data for year 1995 and 2005, they found that oil abundance increases life expectancy and reduces infant mortality, although the effects are not significant using the year 2005 data.

${ }^{25}$ Note that in Besley and Kudamatsu do not control for initial health in their regressions. Following Bloom et al. (2009), we control for initial health in our regressions.

${ }^{26}$ Using data from the United Nations, however, the estimated effect on life expectancy becomes less significant (point estimate $=-0.671$ with standard error $=0.285$, and hence significant at the 5\% level). The effect on infant mortality becomes even insignificant (point estimate $=0.019$, with standard error $=0.038$ ).
} 
since the 1980s. The negative oil effect on health since the 1980s should not be interpreted as a curse of oil abundance, because it was a period of dramatic decline in oil prices rather than a boom period of new discoveries. ${ }^{27}$ Despite the effect on population growth, our cross-country results shed considerable doubt on the claim that oil is a curse because on average the larger population from oil-rich countries is neither trapped in poverty nor poor health.

\section{Oil and Development: New Panel Evidence}

In this section, we study the oil-development relationship using panel estimations. To our knowledge, much of the literature, with the exception of Manzano and Rigobon (2001), employs either OLS or instrumental variables estimation procedures without fixed effects.

There are two potential caveats to our cross-country before-after comparison. First, we identify the country United Arab Emirates (UAE) as an extreme outlier in our sample. While the estimated effect on population is robust to the inclusion of this outlier, the estimated economic impact of oil discovery is not. We argue in the appendix that the case of the UAE is mostly driven by measurement error, and even including this noisy data point we find little robust negative association between oil abundance and economic growth. In this sense, our crosscountry analysis strengthens Alexeev and Conrad's conclusion that the curse of oil is elusive, even after controlling for initial income.

Second, in any cross-country regression, we can never be sure whether we are controlling for all confounding factors. All previous studies from the resource curse literature treat oil abundance as exogenous. However, David and Wright (1997) argue that natural resource abundance (measured by deposit at a given point in time) depends on geological good fortune as well as favorable legal, institutional, and political structures. Our measure of oil abundance improves upon the measures from previous studies by exploiting geologically-determined initial oil endowment, which is arguably more exogenous than other measures, such as current oil production or reserves. Nonetheless, even variation in the estimated oil endowment may not be completely exogenous when geologists' estimates are based on geological information as well as oil discovery history. For example, if countries with superior institutions are more successful in

\footnotetext{
${ }^{27}$ The price of crude oil fell from more than $\$ 100$ in the early 1980s to less than $\$ 20$ per barrel towards the end of the 1980s in 2008 dollars. At the global level, oil discoveries have been declining since the peak discovery period during the early 1960s.
} 
oil exploitation (Bohn and Deacon, 2000), and such institutions generate both higher economic growth and larger oil discovery, this omitted variable bias will introduce an upward bias to our estimated impact on economic growth. Moreover, the problem may also create downward bias in the case of population growth if such institutions also encourage human capital accumulation, which at the end reduces population growth. ${ }^{28}$

An alternative approach that can better address the omitted variable bias problem is to use panel method. While the initial oil endowment for each country is a fixed factor, there is substantial time-series variation in oil rent because of fluctuation in oil prices as well as development of new oil fields and depletion of old ones. Indeed, to test the big-push hypothesis, which contends that resource booms cause industrialization because they raise incomes and therefore demand for domestic manufactures, or the Dutch disease-type argument, which argues that resource booms cause factors to shift away from the manufacturing sector, the relevant source of variation is changes in the size of oil rent over time. However, when there is not sufficient time-series variation in oil rent over a short period of time, the dynamic panel estimation procedure may exaggerate the measurement error bias, and bias towards zero the oil coefficient in our case. In other words, there is a tradeoff between reducing the bias attributable to omitted heterogeneity and reducing the extent of bias from measurement error. ${ }^{29}$ Thus, our panel analysis should not be viewed as a better substitute to our cross-country analysis; rather, they are complementary to each other. In particular, to the extent that fixed-effects estimations understate the impact of steady-state determinants of growth because of attenuation bias, exploiting within-country variation provides a lower bound of the oil impact.

\subsection{Panel Evidence on Oil Abundance and Development}

For the panel estimation, we consider the following simple growth model:

$$
\mathrm{INCOME}_{\mathrm{it}}=\beta_{1}+\beta_{2} \mathrm{INCOME}_{\mathrm{i}, \mathrm{t}-\tau}+\beta_{3} \mathrm{OIL}_{\mathrm{it}}+\mathrm{X}_{\mathrm{it}}{ }^{\prime} \beta_{4}+\delta_{\mathrm{i}}+\mu_{\mathrm{t}}+\varepsilon_{\mathrm{it} .}
$$

\footnotetext{
${ }^{28}$ In general, to the extent that all cross-country studies (including ours) on the resource curse problem suffer from this potential omitted variable bias, where the omitted factor is positively correlated with resource abundance and economic growth, but negatively correlated with population growth, these estimates will overstate the growthenhancing impact of oil and understate the Malthusian effect.

${ }^{29}$ For example, using Monte Carlo simulations to estimate growth regressions derived from the Solow model, Hauk and Wacziarg (2009) find that cross-country estimations tend to bias the human capital parameter slightly upward, while panel estimations severely bias this coefficient downwards.
} 
In our baseline specification, we use data at 5-year intervals (i.e. $\tau=5$ ). We show in section 5 that similar results are obtained using both higher and lower frequencies data. The variable of interest oil is measured as the time average of per capita oil rent (measured in $\$ 100,000$ per capita, 1990 dollars) over the relevant growth period. In our sensitively analysis, we show that similar results are obtained when we instrument oil rent by oil reserves. In our panel regressions, we also control for time-averaged democracy and war, because political stability may affect both oil extraction and growth. ${ }^{30}$ The $\delta_{\mathrm{i}}$ ' s denote a full set of country dummies and the $\mu_{\mathrm{t}}$ 's denote a full set of time effects that capture common shocks to the dependent variable for all countries at time t. $\varepsilon_{\mathrm{it}}$ is an error term, capturing all other omitted factors, with $\mathrm{E}\left(\varepsilon_{\mathrm{it}}\right)=0$ for all $\mathrm{i}$ and $\mathrm{t}$.

Because of the presence of lagged dependent variable in standard growth regression, the standard fixed-effects estimator becomes consistent only when the number of periods increases to infinity. We, therefore, estimate dynamic panel data models that account for the endogeneity of the lag dependent variable. First, we use the methodology proposed by Anderson and Hsiao (1982), which is to time difference equation (2), to obtain

$$
\Delta \mathrm{INCOME}_{\mathrm{it}}=\beta_{1}+\beta_{2} \Delta \mathrm{INCOME}_{\mathrm{i}, \mathrm{t}-\tau}+\beta_{3} \Delta \mathrm{OIL}_{\mathrm{it}}+\Delta \mathrm{X}_{\mathrm{it}}{ }^{\prime} \beta_{4}+\Delta \mu_{\mathrm{t}}+\Delta \varepsilon_{\mathrm{it}}
$$

where the country fixed effects are removed by time differencing. When there is no serial correlation in the original $\varepsilon_{\mathrm{it}}$, and hence no second order serial correlation in $\Delta \varepsilon_{\mathrm{it}}, \mathrm{INCOME}_{\mathrm{i}-2 \tau}$ is uncorrelated with $\Delta \varepsilon_{\text {it }}$ and hence can be used as an instrument for $\Delta \mathrm{INCOME}_{\mathrm{i}-\tau}$. Another approach, which exploits the assumption of no further serial correlation in $\varepsilon_{\mathrm{it}}$, and hence produces more efficient estimates when all the moment conditions are valid, was developed by Arellano and Bond (1991). In our GMM estimation, we also treat other control variables as predetermined, ${ }^{31}$ so that the second and further lags can be used as instruments for the firstdifferenced control variables. Under this GMM method, we can also test for the assumptions of no serial correlation and overidentifying restrictions. ${ }^{32}$

\footnotetext{
${ }^{30}$ Our estimates are similar without controlling for these political variables.

${ }^{31}$ In other words, while current shocks are assumed to be uncorrelated with current and past values of oil rent, we allow for feedback effects from lagged dependent variables (or lagged errors) to current and future values of oil rent.

${ }^{32}$ We do not consider the system-GMM estimator (Arellano and Bover, 1995) because it requires additional identifying restrictions which are not appealing in our context. In particular, it uses time-differenced instruments for the level equations. In our setting, it requires five-year changes in oil-rent being orthogonal to the growth country fixed effect. We think this assumption is likely to be violated because political instability contributes to supply disruptions and price volatility. Oil-countries such as Algeria, Nigeria, and Iraq are some of the obvious examples.
} 
Our panel results on oil and development are reported in Table 6, using data from the 1970-2000 period. ${ }^{33}$ For consistency, income and population data are taken from the Maddison dataset. We show in section 5 that similar results are obtained using the Penn World data. Each row corresponds to the regression for each dependent variable, namely, total GDP, population, and GDP per capita. Our base sample is an unbalanced sample. As a point of reference, column (1) first presents the simple pooled OLS estimates. According to column (1), one might conclude that oil is a curse and it leads to a Malthusian trap, because it shows that higher rent induces lower GDP per capita growth and higher population growth. However, recall from Figure 1 that oil-rich countries experienced negative growth during the 1980s. Making a cross-country comparison over that period, we are essentially comparing the growth of an oil-rich country which suffered from a negative income shock with the growth of a non-oil country which, if anything, benefited from the lower oil prices. Apparently, oil-producing countries experienced negative economic growth not because they became more oil abundant; rather, it is because their oil endowment became less valuable. If short-to-medium oil impact on growth is to be estimated, the appropriate empirical framework is fixed-effects estimation which exploits within-country variation in the value of oil rent. Column (2) shows that once we focus on within-country variation, the curse of oil disappears. In particular, the effect on total GDP becomes positive (although statistically insignificant), and the negative effect on GDP per capita becomes almost ten times smaller and also insignificant. The only robust effect is the effect on population. Because of the presence of lagged dependent variable, however, this simple fixed-effects estimation is not consistent.

Column (3) shows that using the Anderson-Hsiao estimator, the economic impact of oil becomes positive, even measured in per capita terms, although the estimate is very imprecise. To improve efficiency, column (4) reports the results using the Arellano-Bond GMM estimator. The positive effect on total GDP growth now becomes highly significant, and the estimated effect on per capita GDP growth becomes less imprecise. In both cases, the effect on population growth is positive and highly significant. For instance, a point estimate of 0.521 from the Arellano-Bond

To the extent that our country fixed effects are capturing time-invarying institutional features which also determine political stability and growth, these moment restrictions are not satisfied.

${ }^{33}$ We use data from the 1970-2000 period as our base sample because there are too few observations during the 1960-1970 period. In section 5, we present robustness check using the unbalanced sample over the 1960-2000 period. 
GMM estimator implies that compared with a no-oil country, collecting $\$ 1,800$ of oil rent per capita a year an average oil-producing country will increase the annual population growth rate by almost 0.2 percentage points.

Columns (5) and (6) report the estimates using a balanced sample of countries from 1970 to 2000. Once again, there is no evidence for the curse of oil, although our panel evidence does not support the big-push theory either. The effect on population is robust to restricting the data to the balanced sample. Finally, the AR(2) test and the Hansen J test indicate that there is no further serial correlation and the overidentifying restrictions are not rejected in both the unbalanced and balanced samples.

\subsection{Panel Evidence on Oil Abundance and Other Demographic and Health Outcomes}

With the robust evidence for the oil-population association from both cross-sectional and panel analyses, we now extend our panel analysis to other demographic and health outcomes. Since the decomposition in population growth requires controlling for initial population but not initial births, deaths, or net migration, the panel estimations of the sources of population growth is straightforward. ${ }^{34}$ To make our estimation comparable with the population growth estimation, we remove the country fixed effects by first differencing.

Panel A of Table 7 summarizes the panel evidence on oil abundance and the sources of population change, using data from the period 1970-2000. Consistent with our earlier crosscountry evidence, oil rent has a positive and significant effect on both the number of births and net migration, with the effect on migration economically more significant in explaining the population growth using both the unbalanced and balanced samples. ${ }^{35}$ The last column shows that oil rent increases fertility in both samples. ${ }^{36}$

\footnotetext{
${ }^{34}$ In particular, the estimates reported in columns [2]-[5] of Table 7 Panel A are obtained following the strategy described in equation (3). Since equation (2) can be thought of as a regression in population growth, the dependent variable in equation (3) can also be interpreted as the change in population growth, which is the sum of changes in births, deaths, and net migration.

${ }^{35}$ Similar to the case of the cross-country analysis, we obtain similar result when we deflate births by current female population, and the estimated effect is smaller when we use standard birth rates. For instance, with the unbalanced sample, the point estimate is 0.004 (standard error $=0.002$, and hence significant at the $5 \%$ level).

${ }^{36}$ There are some missing values for the fertility data especially in the year 1975 . When missing, fertility for year 1975 was imputed based on 1972 and 1977 data under the assumption of constant rate of growth. A similar imputation was done for 1985, and 1995.
} 
From Table 5 we have seen some cross-country evidence that citizens from oil-rich countries in general do not gain less in health outcomes except during the 1980-2000 period when life expectancy is negatively correlated with oil abundance. But this does not mean oil abundance is bad for health, because oil rent was indeed lower when oil prices collapsed. Panel B confirms this using the standard fixed-effects method. Because of the limitation of data, we focus on the unbalanced samples, with data at 5- and 10-year intervals over the 1960-2000 period. Exploiting within-country variation in oil rent, Panel B of Table 7 shows that oil rent is indeed negatively correlated with infant mortality and positively correlated with life expectancy in both specifications. ${ }^{37}$

\section{Sensitivity Analysis}

A range of sensitivity checks is performed. Table 8 summarizes the results from the crosscountry before-after analysis. The oil coefficients for the baseline specification, with dependent variables total GDP growth, population growth, and per capita GDP growth, are reproduced on the top row of Table 8. All regressions are run with the full set of controls. To save space, we report only the growth results three decades after the peak discovery year.

A common concern in all cross-country results is whether they are driven by outlying observations. We drop the top 10 oil-rich countries (measured by their endowment per capita) one at a time, and in all cases the oil impact remains highly significant. For example, dropping either Libya or Iraq, the two most oil-rich countries in our sample, the estimated effects become slightly larger, which suggests the possibility of a nonlinear effect. ${ }^{38}$ Including a squared term of oil endowment in the regressions indicates that the growth effects of oil discovery indeed exhibit decreasing returns. ${ }^{39}$ Focusing on oil countries only, we find that the economic impact of oil remains highly significant, although the population effect becomes very imprecise when the sample size reduces by half. The results are very similar when oil endowment is measured in log,

\footnotetext{
${ }^{37}$ Again, we find more significant effects using data from the United Nations. For instance, using 5-year data, the point estimate for the life expectancy regression is 0.207 (standard error $=0.088$, and hence significant at the 5\% level), and the point estimate using 10-year data is 0.560 (standard error $=0.187$, and hence significant at the $1 \%$ level). Similarly, the effect on infant mortality is always negative and significant at the $1 \%$ level.

${ }^{38}$ The top 10 oil countries in our sample are Libya, Iraq, Venezuela, Oman, Iran, Trinidad Tobago, Equatorial Guinea, Algeria, United States, and Angola. Dropping each of them one at a time, the estimated effect on population growth ranges from 0.175 to 0.353 , and the estimated effect on per capita GDP growth ranges from 0.747 to 1.231. All these estimates are significant at least at the $5 \%$ level.

${ }^{39}$ In all three regressions, however, the oil coefficients are jointly significantly at the $1 \%$ level.
} 
or when we use another independent estimate of undiscovered oil resource from the US Geological Survey.

In addition to the concern of outliers, another key drawback of cross-country analysis is the omitted variable problem. The rest of the table reports the results when we add more control variables. Controlling for dummies for legal origin, landlock, or tropical barely changes anything. The results are also robust to adding current rule of law as a control variable. First, it is important to note that, ideally, one would like to control for initial institution before the peak discovery year and the current institution should be an outcome variable. However, in practice, because of the availability of the data we can only use current measure, and hence to the extent that institution is endogenous, controlling for this rule of law variable is subject to both endogeneity bias as well as measure error problem. Following Alexeev and Conrad (2009a), we instrument the rule of law variable by latitude, the fraction of English language speakers, and the fraction of European language speakers. ${ }^{40}$ Controlling for this instrumented measure of institutional quality, the positive economic and population impacts of oil remain highly significant statistically, suggesting our analysis may not be subject to severe omitted variable bias. $^{41}$

A different set of robustness checks is performed for our panel analysis. Our baseline estimates using the Arellano-Bond GMM estimator with the balanced sample over the 19702000 period are first reproduced on the top row of Table 9. The next two rows examine alternative samples. To maximize the number of observations, we consider using the unbalanced sample over the 1960-2000 period. Alternatively, we restrict to the balanced sample over the 1970-1990 period, when the oil market experienced its boom and bust. In both samples, there is a robust effect on population growth and no evidence for the curse of oil. Another way to increase the number of observations is to use higher-frequency data. At 3-year intervals, the effect on population indeed becomes slightly stronger, while the economic impact of oil remains insignificant. Using 7-year intervals, one the other hand, we obtain both a significant effect on

\footnotetext{
${ }^{40}$ In all regressions, the instruments are strong and they pass the overidentification test. For example, for the GDP per capita regression, the partial R-squared of the excluded instruments is 0.119 (F-statistics $=5.6$ ). The Hansen J pvalue is 0.398 , and hence it fails to reject the null hypothesis that the instruments are exogenous.

${ }^{41}$ Note that here the coefficients become larger mainly because of the change in sample, instead of the inclusion of the control. Indeed, in this smaller sample, the estimated effect on economic growth is indeed slightly larger without controlling for the rule of law variable.
} 
population and a marginally significant impact on total GDP growth. Similar results are obtained when using the Penn World data, instead of the Maddison data.

The rest of the table reports other specification tests. Since production may be endogenous to growth, in addition to using lagged oil rent as instruments we use lagged oil reserves as an instrument for current oil rent, because from discovery to first production there is a development lag ranging from about two years for onshore major fields to around 10 years for offshore oilfields (Laherrere, 1998). Once again, we obtain a significant effect on population growth and a marginally significant impact on total GDP growth. ${ }^{42}$ Finally, instead of using GDP and population information every fifth year, we check the results with five-year averaged data. The estimate in each column is similar to its corresponding estimate from the baseline specification.

\section{Interpretation and Concluding Remarks}

This study uses a unique dataset on worldwide oil discoveries and extractions to provide new evidence of the impact of oil abundance on development. In particular, we exploit betweencountry variations in the timing and size of oil discoveries and within-country variation in oil rent over time to identify the causal effect of oil abundance on economic growth, population growth, birth and fertility rates, net migration rate, death and infant mortality rates, and life expectancy. Contrary to the oil-curse hypothesis, we find that there is no robust evidence of a negative relationship between oil endowment and economic development, even after controlling for initial income. Rather, based on both cross-country and panel evidence, we find that higher oil rent is robustly associated with higher population growth. Although we do find some evidence that oil abundance is associated with higher fertility rate, the mechanism in the case of oil is more subtle than the traditional Malthusian one because migration plays an even more prominent role in explaining the oil-induced population growth. Moreover, we show that focusing on material gain may understate the welfare gain from oil abundance, because oil-rich countries gain more in longevity and infant mortality reduction.

\footnotetext{
${ }^{42}$ In all regressions, the instruments pass the overidentification test. For example, for the GDP per capita regression, the Hansen J p-value is 0.164 , and hence it fails to reject the null hypothesis that the instruments are exogenous.
} 
Indeed, when extreme outliers are dropped, our cross-country before-after comparison shows that oil discovery has a significant positive effect on economic growth. On the other hand, although we find some panel evidence that higher oil rent is associated with higher total GDP growth, there is little robust evidence that higher oil rent leads to a significant increase in per capita GDP growth. These cross-country and panel results are consistent with the existence of the omitted variable bias in the former and the exacerbation of attenuation bias in the latter. While the exact magnitude of the positive economic impact of oil is less precisely estimated, our results reject the hypothesis that oil abundance is an economic curse.

Recall from Table 2 that our sample of countries with different oil endowment is balanced across a wide variety of observables, and according to Table 8 our cross-country estimates are robust to adding additional controls, including proxy for institution quality. These results indicate that there is little evidence for severe omitted variable bias from our crosscountry estimates. However, we do find strong panel evidence of a positive oil impact on population growth but not on economic growth, suggesting measurement error alone is not likely to explain all the discrepancies between our cross-sectional and panel results. One interpretation from our panel results is that at least in the short-to-medium run, oil abundance has a stronger impact on population growth than on economic growth.

Our finding of the oil-induced population growth might seem to be consistent with the view of some Middle East scholars that the "oil decade" was a "lost demographic decade" for the overpopulated Arab countries, as various pro-natalist measures have been taken by these governments to maintain their high fertility rates (Winckler, 2009). In a recent paper, Manuelli and Seshadri (2009) find that differences in productivity and taxes explain a significant fraction of differences in international fertility. However, it is important to note that while we argue that the oil effects on population growth and economic development are causal, we do not argue that there is necessarily a negative effect of population on economic growth and welfare. The mechanical relationship between larger population and lower capita GDP is an accounting one. Our results, therefore, do not imply that an oil-rich country will be better off if a birth-control policy is implemented or immigration is restricted.

First, although birth rates are higher in oil-rich countries, our results show this effect is small in magnitude and a significant fraction of population growth is explained by migration. 
The mechanism of population growth is therefore different from the standard Malthusian one. Foreigners working in many of the Middle East oil-rich countries are attracted to these countries because there is a demand for young productive workforce from the oil sector. For any period during which a country experiences substantial immigration, growth in per capita income also tends to understate actual growth in economic welfare when the immigrants enter at an income lower than the average (Friedman, 1974). To the extent that these new migrants have lower income initially but their income converges to the rest of the population over time, our crosscountry and panel results on economic growth are also consistent with the classical interpretation that time series data tend to reflect short-run responses whereas cross sections data tend to yield long-run responses (Kuh, 1959).

Second, both of our cross-sectional and panel results also indicate that citizens from oilrich countries benefit from larger health improvements, which again contradicts a pure Malthusian mechanism by which there is a negative feedback from the size of population to the standard of living because of the existence of some fixed resource. The gain in longevity and reduction in infant mortality suggest that our panel results on economic growth are likely to understate the overall welfare gain from oil abundance. Citizens from oil-rich countries gain in these health outcomes either from higher personal income, ${ }^{43}$ or through subsidized health care financed by their state's oil revenue. While it is debatable whether better health can help promote economic growth in the long run when heath improvements are accompanied by population increases (Acemoglu and Johnson, 2007; Jena et al. 2008), our analysis suggests that despite the positive oil effect on population growth, oil-rich countries do not suffer from the Malthusian trap and overall oil abundance is an economic blessing rather than a curse.

\footnotetext{
${ }^{43}$ In an interesting recent study, Acemoglu et al. (2009) find that an increase in income induced by an oil price shock increases health expenditure, although the income elasticity is less than one.
} 


\section{Appendix A: Data Description and Sources}

Our oil discovery and extraction data are obtained from Dr. Colin Campbell at the Association for the Study of Peak Oil (ASPO), a non-profit organization that is devoted to gathering industrial data to study the dates and impact of the peak and decline of world oil. ${ }^{44}$ The dataset contains the years and sizes of oil discoveries for the top 61 oil countries over the period 19302003. Information on cumulative discovery and production before 1930 is also available. These enable us to construct a long panel of oil reserves. While oil exploration and extraction activities extend over time, a country's major discoveries are usually concentrated in a few years, known as the peak discovery period. For each oil-producing country, the dataset provides information on the year when the oil discovery peaked.

Moreover, the dataset provides for each country an estimate of the total oil-initially-inplace, which is determined by geology and hence presumably exogenous. Knowledge about cumulative discovery and cumulative wildcats also contribute to the estimate. According to geologist Dr. Campbell, who compiled the ASPO oil dataset, the ultimate recoverable reserves (i.e. the original endowment of reserves) is the sum of (a) cumulative production, (b) reserves, and (c) yet-to-find (i.e. the amount of conventional oil remain to be discovered). Based on his industrial raw data at the individual oil-field level, his extensive geology knowledge, and his industrial consulting experience, adjustments were first made to (a) and (b) to correct for misreporting in the public data. In particular, he estimated the "P50" oil reserves by country ("P50" reserves are those with a notional $50 \%$ probability, i.e., being equally likely to see downward revision as upward revision with time). He then combined several techniques to obtain statistical estimates of the yet-to-find. First, he extrapolated published production figures for older oil fields that have begun to decline. Second, he plotted and extrapolated over time the amount of oil discovered so far in some regions against the cumulative number of exploratory wells drilled there. Because larger fields tend to be found first-they are simply too large to miss - the curve is hyperbolic which rises rapidly and then flattens, eventually reaching a theoretical maximum. Third, other statistical techniques involving size distributions and geological habitats

\footnotetext{
${ }^{44}$ One advantage of this dataset over public data is that adjustments are made to remove any identified nonconventional oil. More importantly, oil reserves, measured in barrels, are computed (instead of reported) using information on previous discoveries and production. These backdate revisions remove any suspicious drastic changes in reserves without any significant discovery being identified and any implausibly unchanged reserves. For other details of this dataset, see Tsui (forthcoming).
} 
also contribute to the estimate. For example, he analyzed the distribution of oil-field sizes in the Gulf of Mexico and other provinces. Ranked according to size and then graphed on a logarithmic scale, the fields tend to fall along a parabola that grows predictably over time. Finally, he checked his estimates by matching his projections for oil production in large areas, such as the world outside the Persian Gulf region, to the rise and fall of oil discovery in those places decades earlier. In particular, each country's future production is modeled as follows: (a) if already past peak, by declining production at the existing decline rate (i.e., by a fixed percentage of the remaining recoverable resource); if prior to peak, by increasing production at an annual growth rate until cumulative production equals half that country's ultimate, and thereafter declining production at the then-existing decline rate; and (c) in the case of the Middle-East "swing" producers, calculating their production, subject to their own resource limits, using a small number of "geopolitical" scenario. He concluded that given that the world has now been thoroughly explored, most future discovery will be in ever smaller fields in currently producing basins.

To check the robustness of the ASPO's estimate of oil endowment, we also use another independent estimate from the US Geological Survey World Petroleum Assessment 2000.

The ASPO dataset covers most oil countries. For the rest of the world, oil endowment is either insignificant or nil. The total discovery amount for each of these countries is imputed by adding cumulative production to reserves, both of which are identified from public data, such as the BP Statistical Review of World Energy. Total oil-initially-in-place is imputed as the amount of total discovery. The peak discovery date is imputed using the regional peak year. Since these countries have less incentive to misreport and the figures are either zero or very small, measurement error is bound to be negligible.

Our panel estimation requires data on oil rent. The ASPO dataset provides information on oil price and oil production for most oil countries since 1930. Public data such as the BP dataset also contains production data since 1965. Finally, cost data are obtained from the World Bank Genuine Savings database. Since the cost data are available only after 1970 and for many countries the cost time series is imputed based on just a few observations, we compute for each country an average cost and apply this average cost throughout the sample period. 
For the before-after comparison, income and population data are taken from Maddison's Statistics on World Population, GDP and Per Capita GDP, 1-2006 AD, because it contains historical data that are needed for our analysis. Birth and fertility rates, death rate, infant mortality rate, and age structure of population are obtained from World Development Indicators. Life expectancy data are taken from the World Bank as well as the United Nations. Other controls include geographic variables of absolute value of latitude, and dummy variables for two geographical regions, as well as demographic variables the fraction of Muslim population, and ethnic and religious fractionalization. In some specifications, we also include democracy as a control variable. Data on latitude are obtained from the Global Development Network Growth Database from the World Bank. Data on Muslims are obtained from the World Christian Database, whereas fractionalization data are taken from Alesina et al. (2003). Democracy data is taken from the Polity IV dataset. In the robustness checks, we also control for other fixed factors, such as legal origin, landlock, and tropical. These data are also obtained from the Global Development Network Growth Database. Finally, war data that we use in the panel estimation is obtained from the UCDP/PRIO Armed Conflict Dataset. 


\section{Appendix B: Further Robustness Checks with United Arab Emirates as an Extreme}

Outlier

Throughout the cross-country analysis, United Arabs Emirates (UAE) is treated as an extreme outlier and is excluded from the sample. According to the ASPO data, UAE has an endowment of 0.773 million barrels per capita. The second, third, and forth largest oil-countries from the sample are Libya, Iraq, and Venezuela, with endowment $0.043,0.038$, and 0.025 million barrels per capita respectively. In per capita terms, therefore, UAE has almost 20 times more oil than these countries. On the other hand, according to the ASPO data, while UAE's first year of oil production was 1962 and it has a peak discovery year of 1964, it was the third richest country in the world in the year 1950, with GDP per capita almost 70\% higher than the United States, according to the Maddison's data. We seriously question the reliability of the UAE's early income data, which is crucial in determining its economic growth and hence the overall economic impact of oil abundance in our regressions given that it is an influential observation.

Appendix Figures A1 and A2 replicate the partial residual plots from Figures 4 and 5, with UAE included in the sample. In sharp contrast to Figures 4 and 5, UAE stands out as an outlier in both Figures A1 and A2. More importantly, while the regression line for the population growth regression remains positive, the per capita GDP regression line becomes negatively sloped once UAE is included in the sample. UAE is an influential observation for the economic growth regression, which most likely signals measurement problems as described above. In particular, the population effect remains positively and significant at the $1 \%$ level in all specifications from one decade to four decades after the peak discovery year. On the other hand, while the effect on per capita GDP growth becomes negative, it is only significant two and three decades after the peak discovery year (with point estimate -0.026 , standard error 0.012 , and point estimate -0.040 , standard error 0.010, respectively), but not significant one and four decades after the peak discovery year. Furthermore, not only the magnitude of the effect is economically small, the effect is also not robust to some alternative specifications. For instance, when oil endowment is measured in log, the effect two decades after the peak discovery year becomes only marginally significant at the $10 \%$ level, and the effect becomes even insignificant when we use median regression. 


\section{References}

Acemoglu, Daron, Amy Finkelstein, and Matthew J. Notowidigdo. "Income and Health Spending — Evidence from Oil Price Shocks.” Manuscript, MIT, 2009.

Acemoglu, Daron and Simon Johnson. "Disease and Development: The Effect of Life Expectancy on Economic Growth." Journal of Political Economy. 115(6), December 2007: 925985.

Alesina, Alberto, Arnaud Devleeschauwer, William Easterly, Sergio Kurlat, and Romain Wacziarg.. "Fractionalization." Journal of Economic Growth. 8(2), June 2003: 155-194.

Alexeev, Michael and Robert Conrad. "The Elusive Curse of Oil." Review of Economics and Statistics. 91(3), August 2009a: 586-598.

Alexeev, Michael and Robert Conrad. "The Natural Resource Curse and Economic Transition." CAEPR Working Paper No. 018-2009, September, 2009b.

Anderson, Theodore W. and Cheng Hsiao. "Formulation and Estimation of Dynamic Models using Panel Data," Journal of Econometrics. 18(1), January 1982: 67-82.

Arellano, Manuel and Stephen Bond. "Some Tests of Specification for Panel Data: Monte Carlo Evidence and an Application to Employment Equations" Review of Economic Studies. 58(2), April 1991: 277-297.

Arellano, Manuel and Olympia Bover. "Another Look at the Instrumental Variable Estimation of Error-Components Models.” Journal of Econometrics. 68(1), July 1995: 29-51.

Aslaksen, Silje. "Oil and Democracy - More than a Cross-Country Correlation?" Journal of Peace Research. forthcoming.

Barro, Robert J. Determinants of Economic Growth: A Cross-County Empirical Study. MIT Press, 1998.

Becker, Gary S., Tomas J. Philipson, and Rodrigo R. Soares. "The Quantity and Quality of Life and the Evolution of World Inequality." American Economic Review. 95(1), March 2005: 277291.

Benjamin, Daniel K. and Levis A. Kochin. "A Proposition on Windfalls and Taxes When Some But Not All Resources are Mobile.” Economic Inquiry. 20(3), July 1982: 393-404.

Besley, Timothy and Masayuki Kudamatsu. "Health and Democracy." American Economic Review: Papers and Proceedings. 96(2), May 2006: 313-318.

Black, Dan, Natalia Kolesnikova, Seth G. Sanders, and Lowell J. Taylor. "Are Children 'Normal'?” FRB of St. Louis Working Paper No. 2008-040C. February 25, 2009.

Bloom, David E., David Canning, and Günther Fink. "Disease and Development Revisited." NBER Working Paper Series, no.w15137 July 2009. 
Bohn, Henning and Robert T. Deacon. "Ownership Risk, Investment, and the Use of Natural Resources.” American Economic Review. 90(3), June 2000: 526-549.

Brunnschweiler, Christa N. and Erwin H. Bulte. "The Natural Resource Curse Revisited and Revised: A Tale of Paradoxes and Red Herrings." Journal of Environmental Economics and Management. 55(3), May 2008: 248-264.

Campbell, Colin J. ASPO Oil Depletion Model. Association for the Study of Peak Oil, 2004.

Chambers, Edward J. and Donald F. Gordon. "Primary Products and Economic Growth: An Empirical Measurement.” Journal of Political Economy. 74(4), August 1966: 315-332.

Easterly, William. "National Economic Policies and Economic Growth: A Reappraisal." in Philippe Aghion and Steven Durlauf, ed., Handbook of Economic Growth. North-Holland: Amsterdam, 2005.

Fargues, Philippe. "Women in Arab Countries: Challenging the Patriarchal System?" Population and Society. 387, Frbruary 2003.

Friedman, Milton. “A Bias in Current Measures of Economic Growth.” Journal of Political Economy. 82(2), March-April 1974: 431-432.

Galor, Oded. "From Stagnation to Growth: Unified Growth Theory." in Philippe Aghion and Steven Durlauf, ed., Handbook of Economic Growth. North-Holland: Amsterdam, 2005.

Griliches, Zvi. "Estimating the Returns to Schooling: Some Econometric Problems." Econometrica. 45(1), Janurary 1977: 1-22.

Hauk William R. and Romain Wacziarg. "A Monte Carlo study of growth regressions.” Journal of Economic Growth. 14(2), June 2009: 103-147.

Hall, Robert E. and Charles I. Jones. "Why Do Some Countries Produce So Much More Output Per Worker Than Others?” Quarterly Journal of Economics. 114(1), February 1999: 83-116.

Jena, Anupam, Casey Mulligan, Tomas J. Philipson, and Eric Sun. "The Value of Life in General Equilibrium.” NBER Working paper No. 14157. July 2008.

Kuh, Edwin. "The Validity of Cross-Sectionally Estimated Behavior Equations in Time Series Applications." Econometrica. 27(2), April 1959: 197-214.

Laherrere, Jean. "Development Ratio Evolves as True Measure of Exploitation — Evaluating Oil and Gas Reserves." World Oil. February 1998: 117-120.

Lane, Philip R. and Aaron Tornell. "Power, Growth, and the Voracity Effect." Journal of Economic Growth. 1(2), June 1996: 213-241.

Lederman, Daniel and William F. Maloney. Natural Resources: Neither Curse Nor Destiny. World Bank Publications, 2006.

Manuelli, Rodolfo E. and Ananth Seshadri. "Explaining International Fertility Differences." Quarterly Journal of Economics. 124(2), May 2009: 771-807. 
Manzano, Osmel and Roberto Rigobon. "Resource Curse or Debt Overhang?" NBER Working Paper No. 8390, July 2001.

McCallum, Bennett T. "Relative Asymptotic Bias from Errors of Omission and Measurement." Econometrica. 40(4), July 1972: 757-758.

Mohammed, Nadeya Sayed Ali. Population and Development of the Arab Gulf States: The Case of Bahrain, Oman and Kuwait. Ashgate Publishing, January 2004.

Papyrakis, Elissaios and Reyer Gerlagh. "Resource Abundance and Economic Growth in the United States.” European Economic Review. 51(4), May 2007: 1011-1039.

Robinson, James A., Ragnar Torvik, and Thierry Verdier. "Political Foundations of the Resource Curse." Journal of Development Economics. 79(2), April 2006: 447-468.

Sachs, Jeffrey D. and Andrew M. Warner. "Natural Resource Abundance and Economic Growth.” NBER Working Paper No. 5398, December 1995.

Sachs, Jeffery D. and Andrew Warner. "The Big Push, Natural Resource Booms and Growth." Journal of Development Economics. 59(1), June 1999: 43-76.

Sala-i-Martin, Xavier X. "I Just Ran Two Million Regressions." American Economic Review. 87(2), Papers and Proceedings of the Hundred and Fourth Annual Meeting of the American Economic Association, May 1997: 178-183.

Sala-i-Martin, Xavier, Gernot Doppelhofer, and Ronald I. Miller. "Determinants of Long-Term Growth: A Bayesian Averaging of Classical Estimates (BACE) Approach." American Economic Review. 94(4), September 2004: 813-835.

Torvik, Ragnar. "Learning by Doing and the Dutch Disease." European Economic Review. 45(2), February 2001: 285-306.

Torvik, Ragnar. "Natural resources, Rent Seeking and Welfare." Journal of Development Economics. 67(2), April 2002: 455-470.

Tsui, Kevin K. "More Oil, Less Democracy: Evidence from Worldwide Crude Oil Discoveries." Economic Journal. forthcoming.

van der Ploeg, Frederick. "Challenges and Opportunities for Resource Rich Economies." CEPR Discussion Papers, No. 5688, 2006.

Weil, David N. and Joshua Wilde. "How Relevant Is Malthus for Economic Development Today?" American Economic Review: Papers and Proceedings. 99(2), May 2009: 255-260.

Winckler, Onn. Arab Political Demography: Population Growth, Labor Migration and Natalist Policies. Sussex Academic Press, 2009.

Wright, Gavin and Jesse Czelusta. "The Myth of the Resource Curse." Challenge. March-April 2004: 6-36. 


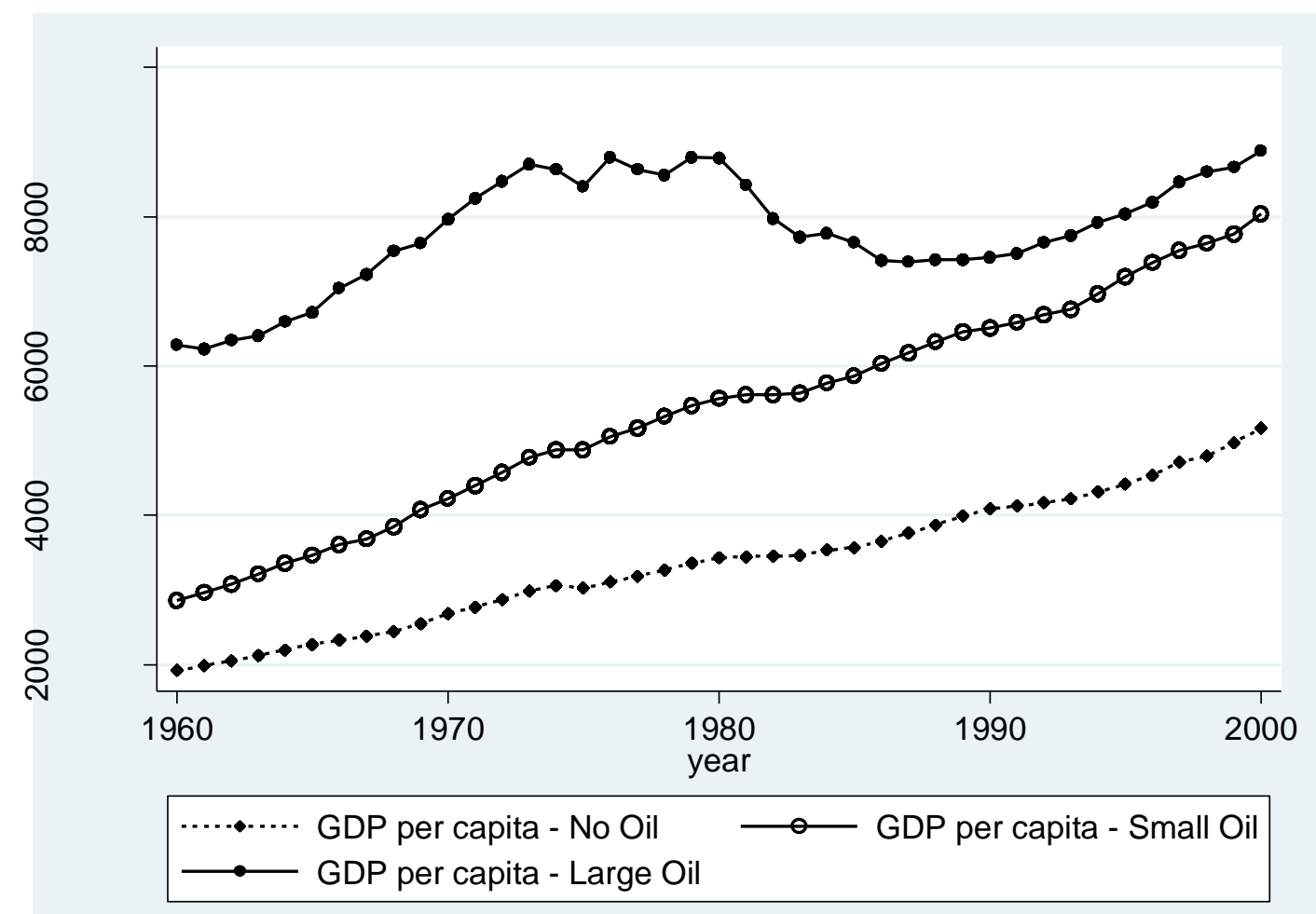

Figure 1

Trends in GDP per capita, by Oil Abundance in 1980 (152 countries) 


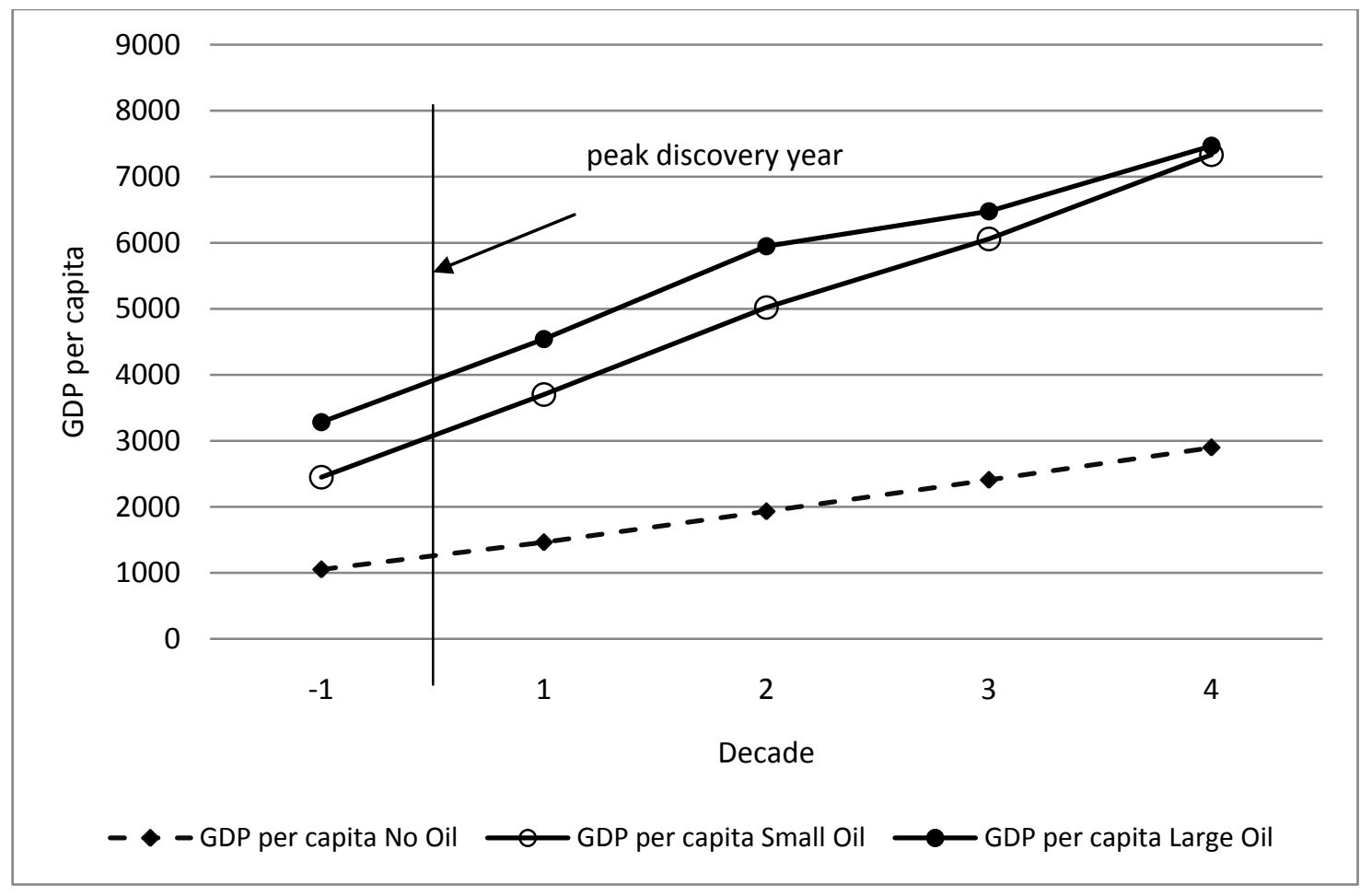

Figure 2

Trends in GDP per capita Before and After Peak Discovery Year, by Initial Oil Endowment

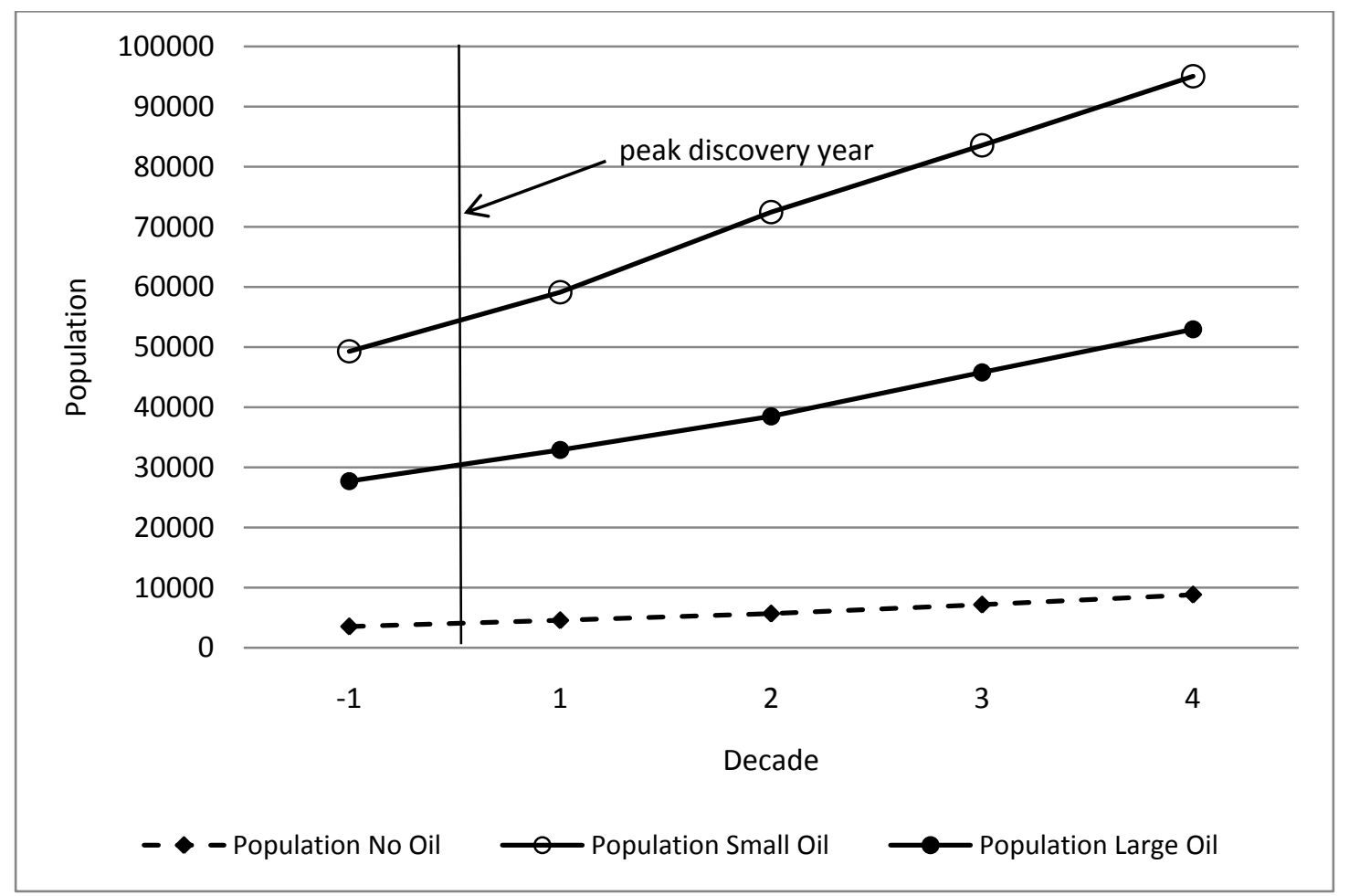

Figure 3

Trends in Population Before and After Peak Discovery Year, by Initial Oil Endowment 


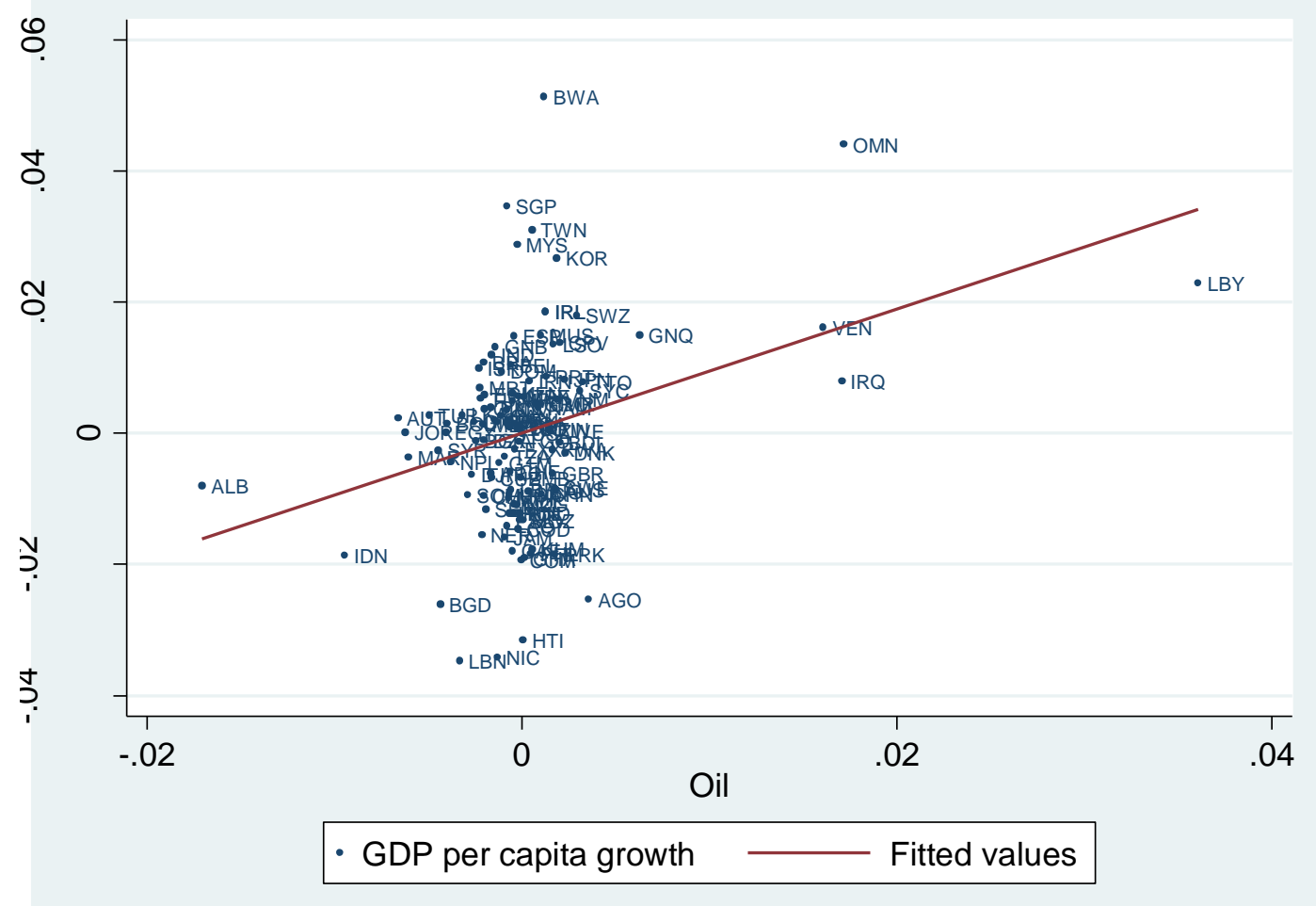

Figure 4

Conditional Correlation between GDP per capita Growth and Oil Endowment 


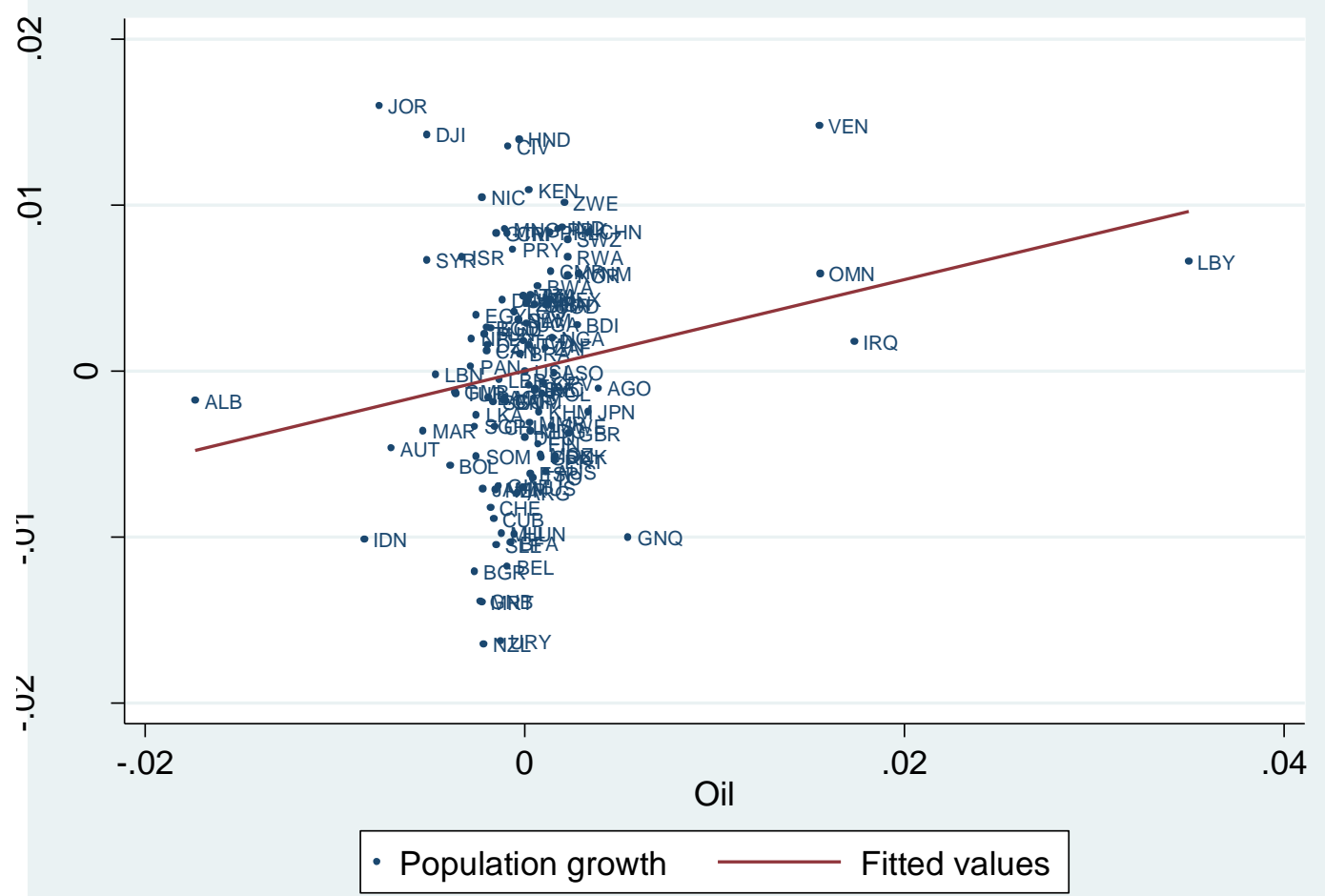

Figure 5

Conditional Correlation between Population Growth and Oil Endowment 
Table 1

Cross-Sectional Estimates of the Association between oil Abundance and Log(GDP per capita)

\begin{tabular}{|c|c|c|c|c|c|}
\hline & {$[1]$} & {$[2]$} & [3] & [4] & {$[5]$} \\
\hline 2000 Cross section & $\begin{array}{l}-0.009 * * \\
(0.002) \\
{[0.825]}\end{array}$ & $\begin{array}{c}0.003 \\
(0.003) \\
{[0.542]}\end{array}$ & $\begin{array}{c}33.226^{* *} \\
(8.673) \\
{[0.557]}\end{array}$ & $\begin{array}{l}2.310 * * * \\
(0.687) \\
{[0.557]}\end{array}$ & $\begin{array}{l}4.647 * * \\
(2.057) \\
{[0.552]}\end{array}$ \\
\hline 1990 Cross section & $\begin{array}{c}-0.004 * * * \\
(0.001) \\
{[0.850]}\end{array}$ & $\begin{array}{l}0.003 * * * \\
(0.001) \\
{[0.545]}\end{array}$ & $\begin{array}{c}22.267 * * \\
(6.970) \\
{[0.552]}\end{array}$ & $\begin{array}{l}1.942 * * * \\
(0.518) \\
{[0.551]}\end{array}$ & $\begin{array}{c}3.614 \\
(2.211) \\
{[0.542]}\end{array}$ \\
\hline 1980 Cross section & $\begin{array}{l}-0.001 \\
(0.001) \\
{[0.904]}\end{array}$ & $\begin{array}{l}0.004 * * * \\
(0.001) \\
{[0.577]}\end{array}$ & $\begin{array}{c}20.611 * * * \\
(4.057) \\
{[0.582]}\end{array}$ & $\begin{array}{l}3.610 * * * \\
(0.393) \\
{[0.581]}\end{array}$ & $\begin{array}{l}7.223 * * \\
(3.544) \\
{[0.552]}\end{array}$ \\
\hline 1970 Cross section & $\begin{array}{c}0.003 \\
(0.004) \\
{[0.949]}\end{array}$ & $\begin{array}{l}0.028 * * * \\
(0.006) \\
{[0.542]}\end{array}$ & $\begin{array}{l}14.284 * * * \\
(3.893) \\
{[0.550]}\end{array}$ & $\begin{array}{l}5.702 * * * \\
(0.712) \\
{[0.546]}\end{array}$ & $\begin{array}{l}9.985 \text { *** } \\
(3.025) \\
{[0.547]}\end{array}$ \\
\hline Log(initial GDP per capita) & yes & no & no & no & no \\
\hline Ethnic Fractionalization & yes & yes & yes & yes & yes \\
\hline Religious Fractionalization & yes & yes & yes & yes & yes \\
\hline$\%$ Muslim & yes & yes & yes & yes & yes \\
\hline Latitude & yes & yes & yes & yes & yes \\
\hline Region Dummies & yes & yes & yes & yes & yes \\
\hline
\end{tabular}

Notes: 114 observations. Robust standard errors are reported in parentheses. Numbers in brackets are the R squared of the regressions. In column [1] and [2] the oil measure is the value of oil reserves normalized by GDP. In column [3] the oil measure is current reserves per capita (million barrels per capita). In column [4] the oil measure is current reserves (million barrels) normalized by population measured in 1960. In column [5] the oil measure is reserves per capita in 1960 (million barrels per capita). Region dummies are East Asia and the Pacific, and Sub-Saharan Africa. 
Table 2

Summary Statistics

\begin{tabular}{|c|c|c|c|c|c|}
\hline \multirow[b]{2}{*}{ Dependent Variables } & \multirow[b]{3}{*}{$\begin{array}{c}0.039 \\
(0.018)\end{array}$} & \multirow{3}{*}{$\begin{array}{c}\text { No Oil } \\
\\
0.037 \\
(0.018)\end{array}$} & \multirow{3}{*}{$\begin{array}{c}\text { Small Oil } \\
\text { Endowment } \\
\\
\\
0.040 \\
(0.015)\end{array}$} & \multirow{3}{*}{$\begin{array}{c}\text { Large Oil } \\
\text { Endowment } \\
\\
0.042 \\
(0.022)\end{array}$} & \multirow{3}{*}{$\begin{array}{c}\begin{array}{c}\text { F- } \\
\text { statistic }\end{array} \\
\\
0.76\end{array}$} \\
\hline & & & & & \\
\hline GDP growth & & & & & \\
\hline Population growth & $\begin{array}{c}0.021 \\
(0.010)\end{array}$ & $\begin{array}{c}0.022 \\
(0.009)\end{array}$ & $\begin{array}{c}0.018 \\
(0.011)\end{array}$ & $\begin{array}{c}0.022 \\
(0.009)\end{array}$ & 1.53 \\
\hline GDP per capita growth & $\begin{array}{c}0.018 \\
(0.017)\end{array}$ & $\begin{array}{c}0.015 \\
(0.018)\end{array}$ & $\begin{array}{c}0.022 \\
(0.016)\end{array}$ & $\begin{array}{c}0.021 \\
(0.017)\end{array}$ & 2.14 \\
\hline \multicolumn{6}{|l|}{ Independent Variables } \\
\hline Oil endowment & $\begin{array}{c}0.002 \\
(0.006)\end{array}$ & $\begin{array}{c}0 \\
(0)\end{array}$ & $\begin{array}{c}4.04 * 10^{-5} \\
\left(4.18 * 10^{-5}\right)\end{array}$ & $\begin{array}{c}0.005 \\
(0.011)\end{array}$ & $19.99 * * *$ \\
\hline Peak discovery year & $\begin{array}{c}1966.282 \\
(10.439)\end{array}$ & $\begin{array}{c}1966.088 \\
(6.550)\end{array}$ & $\begin{array}{c}1967.636 \\
(8.598)\end{array}$ & $\begin{array}{c}1965.294 \\
(16.086)\end{array}$ & 0.49 \\
\hline Log(initial GDP) & $\begin{array}{c}9.167 \\
(2.097)\end{array}$ & $\begin{array}{c}7.904 \\
(1.691)\end{array}$ & $\begin{array}{l}10.802 \\
(1.448)\end{array}$ & $\begin{array}{c}9.699 \\
(1.944)\end{array}$ & $37.88 * * *$ \\
\hline Log(initial population) & $\begin{array}{c}8.568 \\
(1.657)\end{array}$ & $\begin{array}{c}7.666 \\
(1.277)\end{array}$ & $\begin{array}{c}9.914 \\
(1.410)\end{array}$ & $\begin{array}{c}8.775 \\
(1.511)\end{array}$ & $29.36 * * *$ \\
\hline Log(initial GDP per capita) & $\begin{array}{c}7.503 \\
(0.973)\end{array}$ & $\begin{array}{c}7.143 \\
(0.937)\end{array}$ & $\begin{array}{c}7.790 \\
(0.878)\end{array}$ & $\begin{array}{c}7.827 \\
(0.937)\end{array}$ & $7.99 * * *$ \\
\hline Ethnic Fractionalization & $\begin{array}{c}0.451 \\
(0.271)\end{array}$ & $\begin{array}{c}0.471 \\
(0.278)\end{array}$ & $\begin{array}{c}0.358 \\
(0.249)\end{array}$ & $\begin{array}{c}0.508 \\
(0.263)\end{array}$ & $3.24 * *$ \\
\hline Religious Fractionalization & $\begin{array}{c}0.416 \\
(0.249)\end{array}$ & $\begin{array}{c}0.414 \\
(0.245)\end{array}$ & $\begin{array}{c}0.423 \\
(0.237)\end{array}$ & $\begin{array}{c}0.414 \\
(0.274)\end{array}$ & 0.02 \\
\hline$\%$ Muslim & $\begin{array}{c}0.244 \\
(0.353)\end{array}$ & $\begin{array}{c}0.212 \\
(0.328)\end{array}$ & $\begin{array}{c}0.187 \\
(0.332)\end{array}$ & $\begin{array}{c}0.350 \\
(0.398)\end{array}$ & 1.91 \\
\hline Latitude & $\begin{array}{c}15.409 \\
(24.233)\end{array}$ & $\begin{array}{c}9.319 \\
(22.663)\end{array}$ & $\begin{array}{c}25.625 \\
(22.888)\end{array}$ & $\begin{array}{c}15.704 \\
(25.310)\end{array}$ & $5.35^{* *}$ \\
\hline Observations (max) & 124 & 57 & 33 & 34 & \\
\hline
\end{tabular}

Notes: Oil countries with oil endowment less than 0.0001356 million barrels per capita are classified under the heading "Small oil endowment". The table reports summary statistics for the largest sample of countries used in Table 3 regressions, however the sample size may be smaller for some variables. The last column reports heteroskedasticity robust $\mathrm{F}$ statistics from tests of equality of means of the three samples. 
Table 3

Oil Endowment and Development: Cross-Country Before-After Comparison

\begin{tabular}{|c|c|c|c|c|c|c|c|c|}
\hline & \multicolumn{2}{|c|}{$\begin{array}{c}\text { One decade after peak } \\
\text { discovery }\end{array}$} & \multicolumn{2}{|c|}{$\begin{array}{c}\text { Two decades after peak } \\
\text { discovery }\end{array}$} & \multicolumn{2}{|c|}{$\begin{array}{c}\text { Three decades after peak } \\
\text { discovery }\end{array}$} & \multicolumn{2}{|c|}{$\begin{array}{c}\text { Four decades after peak } \\
\text { discovery }\end{array}$} \\
\hline & [1] & [2] & [3] & [4] & [5] & {$[6]$} & [7] & {$[8]$} \\
\hline GDP growth & $\begin{array}{c}1.881 \\
(1.273) \\
{[124 ; 0.39]}\end{array}$ & $\begin{array}{c}1.617 \\
(1.302) \\
{[124 ; 0.45]}\end{array}$ & $\begin{array}{c}1.517 * * * \\
(0.384) \\
{[122 ; 0.33]}\end{array}$ & $\begin{array}{c}1.316^{* * *} \\
(0.373) \\
{[122 ; 0.44]}\end{array}$ & $\begin{array}{c}1.165^{* * * *} \\
(0.314) \\
{[114 ; 0.21]}\end{array}$ & $\begin{array}{c}1.121^{* * *} \\
(0.285) \\
{[114 ; 0.36]}\end{array}$ & $\begin{array}{l}0.770 * * \\
(0.334) \\
{[80 ; 0.12]}\end{array}$ & $\begin{array}{l}0.724 * * \\
(0.293) \\
{[80 ; 0.32]}\end{array}$ \\
\hline Population growth & $\begin{array}{c}0.276^{* * *} \\
(0.087) \\
{[124 ; 0.23]}\end{array}$ & $\begin{array}{c}0.096 \\
(0.122) \\
{[124 ; 0.42]}\end{array}$ & $\begin{array}{c}0.372 * * * \\
(0.075) \\
{[122 ; 0.23]}\end{array}$ & $\begin{array}{c}0.213 * \\
(0.113) \\
{[122 ; 0.47]}\end{array}$ & $\begin{array}{c}0.412 * * * \\
(0.073) \\
{[114 ; 0.29]}\end{array}$ & $\begin{array}{c}0.275^{* *} \\
(0.111) \\
{[114 ; 0.53]}\end{array}$ & $\begin{array}{l}0.348 * * * \\
(0.083) \\
{[80 ; 0.26]}\end{array}$ & $\begin{array}{l}0.242 * \\
(0.125) \\
{[80 ; 0.50]}\end{array}$ \\
\hline $\begin{array}{l}\text { GDP per capita } \\
\text { growth }\end{array}$ & $\begin{array}{c}1.463 \\
(1.265) \\
{[124 ; 0.33]}\end{array}$ & $\begin{array}{c}1.562 \\
(1.276) \\
{[124 ; 0.39]}\end{array}$ & $\begin{array}{c}1.068 * * * \\
(0.394) \\
{[122 ; 0.23]}\end{array}$ & $\begin{array}{c}1.191 * * * \\
(0.368) \\
{[122 ; 0.42]}\end{array}$ & $\begin{array}{c}0.726 * * \\
(0.289) \\
{[114 ; 0.13]}\end{array}$ & $\begin{array}{c}0.946 * * * \\
(0.250) \\
{[114 ; 0.40]}\end{array}$ & $\begin{array}{c}0.397 \\
(0.291) \\
{[80 ; 0.09]}\end{array}$ & $\begin{array}{c}0.617 * * \\
(0.250) \\
{[80 ; 0.42]}\end{array}$ \\
\hline
\end{tabular}

Notes: Oil wealth is measured by oil endowment in million barrels per capita. All regressions control for the dependent variable before peak discovery year, and decade fixed effects. In addition, columns [2], [4], [6], and [8] include Ethnic fractionalization, Religious fractionalization, \% Muslim, Latitude, and Region dummies. The regions included are East Asia and the Pacific, and Sub-Saharan Africa. Robust standard errors are reported in parentheses. The number of observations and the R squared from the regressions are reported in square brackets. 
Table 4

Decomposition of the Oil-Induced Population Growth: Cross-Country Comparison

\begin{tabular}{|c|c|c|c|c|c|}
\hline & $\begin{array}{c}\text { Population Change } \\
{[1]}\end{array}$ & $\begin{array}{c}\text { Births } \\
{[2]}\end{array}$ & $\begin{array}{c}\text { Deaths } \\
\text { [3] }\end{array}$ & $\begin{array}{c}\text { Net Migration } \\
{[4]}\end{array}$ & $\begin{array}{c}\text { Fertility } \\
{[5]}\end{array}$ \\
\hline $1960-1980$ & $\begin{array}{c}0.299 * * * \\
(0.046) \\
{[86 ; 0.85]}\end{array}$ & $\begin{array}{c}0.483 * * * \\
(0.087) \\
{[86 ; 0.92]}\end{array}$ & $\begin{array}{c}0.156^{* * *} \\
(0.035) \\
{[86 ; 0.77]}\end{array}$ & $\begin{array}{c}1.881 * * * \\
(0.225) \\
{[86 ; 0.43]}\end{array}$ & $\begin{array}{c}39.296 * * * \\
(7.228) \\
{[86,0.92]}\end{array}$ \\
\hline $1970-1990$ & $\begin{array}{c}0.237 * * * \\
(0.069) \\
{[106 ; 0.84]}\end{array}$ & $\begin{array}{c}0.261 * * \\
(0.106) \\
{[106 ; 0.88]}\end{array}$ & $\begin{array}{c}0.029 \\
(0.028) \\
{[106 ; 0.75]}\end{array}$ & $\begin{array}{c}1.703 * * * \\
(0.399) \\
{[106 ; 0.60]}\end{array}$ & $\begin{array}{c}12.377 \\
(8.799) \\
{[106 ; 0.86]}\end{array}$ \\
\hline $1980-2000$ & $\begin{array}{c}0.149 * * * \\
(0.048) \\
{[115 ; 0.76]}\end{array}$ & $\begin{array}{c}0.147 * * * \\
(0.043) \\
{[115 ; 0.89]}\end{array}$ & $\begin{array}{c}0.026 \\
(0.018) \\
{[115 ; 0.80]}\end{array}$ & $\begin{array}{c}1.109 * * * \\
(0.275) \\
{[115 ; 0.54]}\end{array}$ & $\begin{array}{c}12.374 * * * \\
(3.904) \\
{[115 ; 0.88]}\end{array}$ \\
\hline $1960-2000$ & $\begin{array}{c}0.330 * * * \\
(0.037) \\
{[85 ; 0.89]}\end{array}$ & $\begin{array}{c}0.979 * * * \\
(0.107) \\
{[85 ; 0.90]}\end{array}$ & $\begin{array}{c}0.139 * * * \\
(0.043) \\
{[85 ; 0.81]}\end{array}$ & $\begin{array}{c}2.284 * * * \\
(0.202) \\
{[85 ; 0.52]}\end{array}$ & $\begin{array}{c}39.694 * * * \\
(5.842) \\
{[85 ; 0.90]}\end{array}$ \\
\hline
\end{tabular}

Notes: The year of the cross-section refers to the year in which the dependent variable was measured. The dependent variable in column 1 is population growth calculated as (log current population -log initial population)/number of years. The dependent variables in columns [2]-[5] are averages calculated from the data available after the initial period. The birth rate (mortality rate/net migration) used in averages was calculated as total births divided by initial population (please see text for further explanations). The independent variable of interest is the initial level of oil reserves measured in million barrels per capita, which represents a 20 years lag in the case of the first 3 rows and a 40 years lag in the last row. All regressions control for the initial level of log population, log GDP per capita, democracy, and age structure of population (i.e. 20 years lag in the first 3 rows, and 40 years lag in the last row). In addition all regressions include ethnic fractionalization, religious fractionalization, \% Muslim, latitude, and region dummies. Regions are East Asia and the Pacific, and Sub-Saharan Africa. Robust standard errors are reported in parentheses. In square brackets are reported the number of observations and the R squared from the regressions. 
Table 5

Oil Reserves and Health: Cross-Country Comparison

\begin{tabular}{ccc}
\hline \hline & Infant Mortality & $\log ($ Life Expectancy $)$ \\
\cline { 2 - 3 } [1] $1960-1980$ & $-0.446^{*}$ & $1.548^{*}$ \\
& $(0.239)$ & $(0.835)$ \\
& {$[79 ; 0.89]$} & {$[85 ; 0.89]$} \\
[2] 1970-1990 & -0.037 & -0.153 \\
& $(0.094)$ & $(0.450)$ \\
& {$[101 ; 0.90]$} & {$[104 ; 0.87]$} \\
[3] $1980-2000$ & $0.123 * * *$ & $-0.712 * * *$ \\
& $(0.043)$ & $(0.268)$ \\
& {$[112 ; 0.94]$} & {$[115 ; 0.91]$} \\
& & -0.168 \\
& & $(0.860)$ \\
& -0.116 & {$[84 ; 0.87]$}
\end{tabular}

Notes: The dependent variable in column [1] is infant mortality (per live births). The independent variable of interest is the initial level of oil reserves measured in million barrels per capita, which represents a 20 years lag in the case of the first 3 rows and a 40 years lag in the last row. All regressions control for the initial level of dependent variable, log population, log GDP per capita, and democracy (i.e. 20 years lag in the first 3 rows, and 40 years lag in the last row). In addition all regressions include Ethnic fractionalization, Religious fractionalization, \% Muslim, Latitude, and region dummies. Regions are East Asia and the Pacific, and Sub-Saharan Africa. Robust standard errors are reported in parentheses. In square brackets are reported the number of observations and the R squared from the regressions. 
Table 6

Oil Rent and Development: Panel Analysis

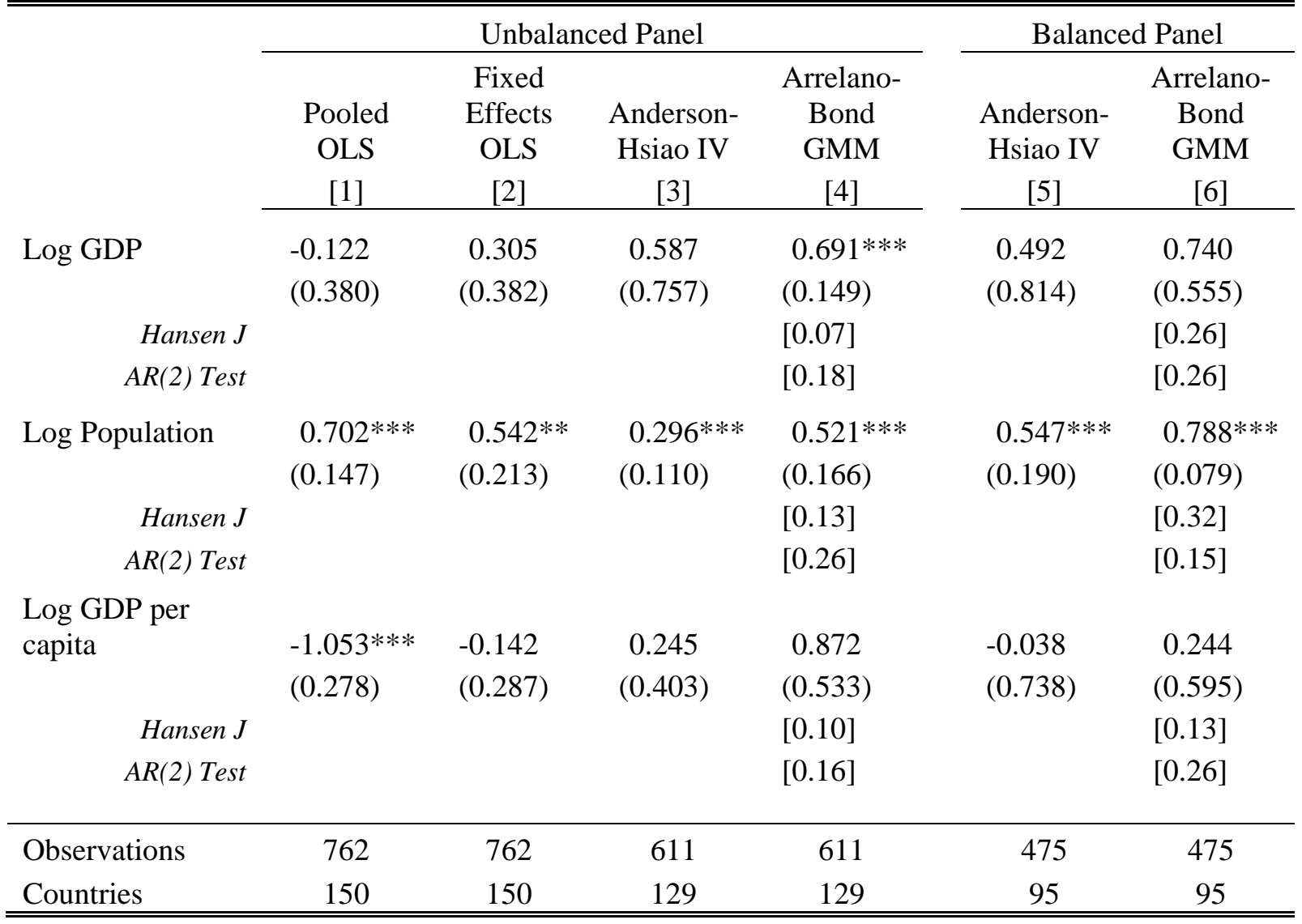

Notes: The regressions run on 5-year data from 1970-2000. The variable of interest is oil rent [(pricecost)*production] computed as average of the 5 years from t-5 to t- 1 and expressed as $\$ 100,000$ per capita. All regressions control for lag dependent variable. Other controls are democracy and war measured as averages of the 5 years from t-5 to t-1, and time fixed effects. Columns [3] and [5] use instrumental variables method of Anderson and Hsiao (1982), where the lag dependent variable in differences is instrumented using the second lag of the dependent variable in levels. Columns [4] and [6] use GMM method of Arellano and Bond (1991). In this specification we make the following identifying assumptions. The lag dependent variable is predetermined and the other control variables oil rent, democracy, and years of war (measured as averages of the 5 years from t-5 to t-1) are not predetermined for the $\varepsilon_{\mathrm{i}, \mathrm{t}}$, but are predetermined for $\varepsilon_{\mathrm{i}, \mathrm{t}+1}$ (which means after 5 years). As a result, the second lag and further lags of dependent variable act as instruments for lag differenced dependent variables, and the second lag and further as instruments for the differenced control variables. [Following the specification described above in the unbalanced panel for the Population and the GDP per capita regressions, the Hansen $\mathrm{J}$ rejects the null that instruments are exogenous. As a result, we report results obtained after excluding the nearest lag in the set of instruments specified above.] Robust standard errors clustered at country level are reported in parentheses. Hansen J statistic reports the p-value of a test of overidentifying restrictions robust to heteroskedasticity. AR(2) Test reports the $\mathrm{p}$-value from a test for second order correlation in differences/first-order correlation in levels of the idiosyncratic error term. 
Table 7

Oil and Population- Panel Analysis

Panel A. Decomposition of the Oil-Induced Population Growth

\begin{tabular}{lccccc}
\hline \hline & Population & Births & Deaths & Net Migration & Fertility \\
& {$[1]$} & {$[2]$} & {$[3]$} & {$[4]$} & {$[5]$} \\
\cline { 2 - 5 } & $0.432 * * *$ & $0.014 * * *$ & $-0.004 * *$ & $0.114 * * *$ & $0.644 *$ \\
Unbalanced & $(0.082)$ & $(0.005)$ & $(0.002)$ & $(0.036)$ & $(0.350)$ \\
Panel & {$[633 ; 135]$} & {$[633 ; 135]$} & {$[633 ; 135]$} & {$[634 ; 135]$} & {$[633 ; 135]$} \\
& & & & \\
Balanced & $0.704 * * *$ & $0.022 * *$ & -0.003 & $0.192 * * *$ & $1.877 *$ \\
Panel & $(0.075)$ & $(0.009)$ & $(0.002)$ & $(0.055)$ & $(1.022)$ \\
& {$[564 ; 117]$} & {$[564 ; 117]$} & {$[546 ; 117]$} & {$[564 ; 117]$} & {$[564 ; 117]$}
\end{tabular}

Notes: Sample: 5-years data for the period 1970-2000. The number of observations and the number of countries are reported in brackets. The variable of interest is oil rent computed as average of the 5 years from t-5 to t- 1 and expressed as $\$ 100,000$ per capita. The birth rate is calculated as number of births divided by initial population (initial population in this context is lag population where 1 lag is equivalent to 5 years). The mortality rate is calculated as number of deaths divided by initial population (initial population in this context is lag population where 1 lag is equivalent to 5 years). Net migration is also normalized by initial population (initial population in this context is lag population where 1 lag is equivalent to 5 years). Column [1] uses GMM method of Arrelano Bond (1991) to replicate the results reported in Table 6 columns [5] and [6] on population data from World Bank Development Indicators. Columns [2]-[5] report OLS specification using first-differenced data (1 lag=5 years). Other controls are democracy and war both computed as averages over 5 years from t-5 to t- 1 , and time fixed effects. Robust standard errors clustered by country are reported in parentheses.

Panel B. Oil Rent and Health

\begin{tabular}{lcccc}
\hline & \multicolumn{2}{c}{ Infant Mortality } & \multicolumn{2}{c}{ Life Expectancy } \\
& 5 -year & 10 -year & 5 -year & 10 -year \\
\cline { 2 - 5 } Oil Rent & $-0.068^{* * *}$ & $-0.188^{* * *}$ & $0.147^{*}$ & $0.469^{* *}$ \\
& $(0.022)$ & $(0.057)$ & $(0.089)$ & $(0.203)$ \\
& {$[966 ; 149]$} & {$[538 ; 145]$} & {$[1010 ; 148]$} & {$[547 ; 144]$} \\
\hline \hline
\end{tabular}

Notes: Robust standard errors clustered by country are reported in parentheses. The number of observations and the number of countries are reported in brackets. Data source for dependent variables: 5-year and 10-year data from World Bank development indicators for period 1960-2000. (1965 data for life expectancy was imputed based on the rate of growth of life expectancy between 1962 and 1967. A similar procedure was used to obtain 1975 data on life expectancy based on the available 1972 and 1977 data on life expectancy.) These regressions control for lag of log population and $\log$ GDP per capita ( 1 lag=5 years for 5-year regressions; 1 lag=10 years for 10-year regressions), for oil rent ( $\$ 100,000$ per capita), democracy, and years of war calculated as averages of the 5 years from t-5 to t-1 in the 5-year regressions or averages of the 10 years from $t-10$ to $t-1$ in the 10 -year regressions. All regressions include country and time fixed effects. 
Table 8

Robustness Check: Cross-Country Before-After Comparison

\begin{tabular}{|c|c|c|c|}
\hline & GDP & Population & GDP per cap \\
\hline [1] Main & $\begin{array}{l}1.121 * * * \\
(0.285)\end{array}$ & $\begin{array}{l}0.275^{* *} \\
(0.111)\end{array}$ & $\begin{array}{l}0.946 * * * \\
(0.250)\end{array}$ \\
\hline [2] Exclude Libya & $\begin{array}{l}1.498 * * * \\
(0.371)\end{array}$ & $\begin{array}{l}0.353 * * \\
(0.158)\end{array}$ & $\begin{array}{l}1.231 \text { *** } \\
(0.387)\end{array}$ \\
\hline [3] Exclude Iraq & $\begin{array}{l}1.237 * * * \\
(0.397)\end{array}$ & $\begin{array}{l}0.322 * * \\
(0.143)\end{array}$ & $\begin{array}{l}1.063 * * * \\
(0.339)\end{array}$ \\
\hline [4] Add a square term & $\begin{array}{l}3.081 * * * \\
(0.742)\end{array}$ & $\begin{array}{c}0.603 \\
(0.430)\end{array}$ & $\begin{array}{l}2.734 * * * \\
(0.746)\end{array}$ \\
\hline $\mathrm{Oil}^{2}$ & $\begin{array}{l}-52.680 * * * \\
(16.836)\end{array}$ & $\begin{array}{l}-8.800 \\
(9.492)\end{array}$ & $\begin{array}{l}-48.397 * * * \\
(17.265)\end{array}$ \\
\hline [5] Oil producing countries only (57) & $\begin{array}{l}0.857 * * \\
(0.319)\end{array}$ & $\begin{array}{c}0.195 \\
(0.156)\end{array}$ & $\begin{array}{l}0.786 \text { *** } \\
(0.263)\end{array}$ \\
\hline [6] Use $\log$ (oil endowment+1) & $\begin{array}{l}1.144 * * * \\
(0.289)\end{array}$ & $\begin{array}{l}0.281 * * \\
(0.113)\end{array}$ & $\begin{array}{l}0.966^{* * * *} \\
(0.255)\end{array}$ \\
\hline [7] Alternative source of oil data & $\begin{array}{l}0.966^{* * * *} \\
(0.225)\end{array}$ & $\begin{array}{l}0.212 * * \\
(0.103)\end{array}$ & $\begin{array}{l}0.838 * * * \\
(0.205)\end{array}$ \\
\hline [8] Control for legal origin & $\begin{array}{l}1.097 * * * \\
(0.318)\end{array}$ & $\begin{array}{l}0.267 * * \\
(0.113)\end{array}$ & $\begin{array}{l}0.940 * * * \\
(0.283)\end{array}$ \\
\hline [9] Add Landlock & $\begin{array}{l}1.116^{* * * *} \\
(0.287)\end{array}$ & $\begin{array}{l}0.278 * * \\
(0.113)\end{array}$ & $\begin{array}{l}0.945^{* * *} * \\
(0.252)\end{array}$ \\
\hline [10] Add Tropical & $\begin{array}{l}1.107 * * * \\
(0.312)\end{array}$ & $\begin{array}{l}0.278 * * \\
(0.107)\end{array}$ & $\begin{array}{l}0.950 * * * \\
(0.275)\end{array}$ \\
\hline [11] Add Rule of law & $\begin{array}{l}1.954 * * * \\
(0.312)\end{array}$ & $\begin{array}{l}0.430 * * \\
(0.167)\end{array}$ & $\begin{array}{l}1.577 * * * \\
(0.289)\end{array}$ \\
\hline
\end{tabular}

Notes: The sample size varies function of the included controls between 106 and 114. In specification [7] the source of data is US Geological Survey. Specification [8] adds 4 dummied for English legal origin, French legal origin, German legal origin, and Scandinavian legal origin (source: World Bank Global Development Network Growth Database). The Landlocked and Tropical variables come from World Bank Global Development Network Growth Database. In specification [11] the variable "Rule of law" is measured in year 2000. Following Alexeev and Conrad (2009a) we instrument this variable using Latitude, English language speakers, and European language speakers. Robust standard errors are reported in parentheses. 
Table 9

Robustness Check: Panel Analysis of Oil Rent and Development

\begin{tabular}{lccc}
\hline \hline & GDP & Population & GDP per capita \\
\cline { 2 - 4 } [1] Main & 0.740 & $0.788^{* * * *}$ & 0.244 \\
& $(0.555)$ & $(0.079)$ & $(0.595)$ \\
[2] Unbalanced Panel 1960-2000 & 0.409 & $0.486^{* * * *}$ & -0.269 \\
& $(0.295)$ & $(0.179)$ & $(0.313)$ \\
[3] Restricted sample 1970-1990 & 1.422 & $0.505^{* * * *}$ & 0.813 \\
& $(0.876)$ & $(0.179)$ & $(0.737)$ \\
[4] 3-year data & 0.282 & $0.300^{* * * *}$ & -0.397 \\
& $(0.554)$ & $(0.049)$ & $(0.731)$ \\
[5] 7-year data (1970-1998) & $2.164 * *$ & $0.706^{* * * *}$ & 0.536 \\
& $(0.882)$ & $(0.235)$ & $(1.216)$ \\
[6] Alternative Data Source & $0.778^{* *}$ & $0.832^{* * * *}$ & 0.346 \\
& $(0.362)$ & $(0.077)$ & $(0.510)$ \\
[7] Add oil reserves as instrument & $0.778^{*}$ & $0.805^{* * *}$ & 0.189 \\
& $(0.456)$ & $(0.060)$ & $(0.465)$ \\
[8] Dependent variable in averages & 0.967 & $0.735^{* * * *}$ & 0.440 \\
& $(0.704)$ & $(0.119)$ & $(1.058)$ \\
\end{tabular}

Notes: Unless otherwise specified the results are obtained on a balanced panel using 5-year data for the period 19702000. The results reported are obtained using a GMM model as describe by Arrelano-Bond (1991) with the same assumptions as those described for Table 6. Specification [2] runs on 800 observations for 129 countries. Specification [3] runs on 285 observations for 95 countries. Specification [6] uses the 1970-2000 GDP and population data from Penn World Tables in a balanced panel with 93 countries. Robust standard errors clustered at country level are reported in parentheses. 


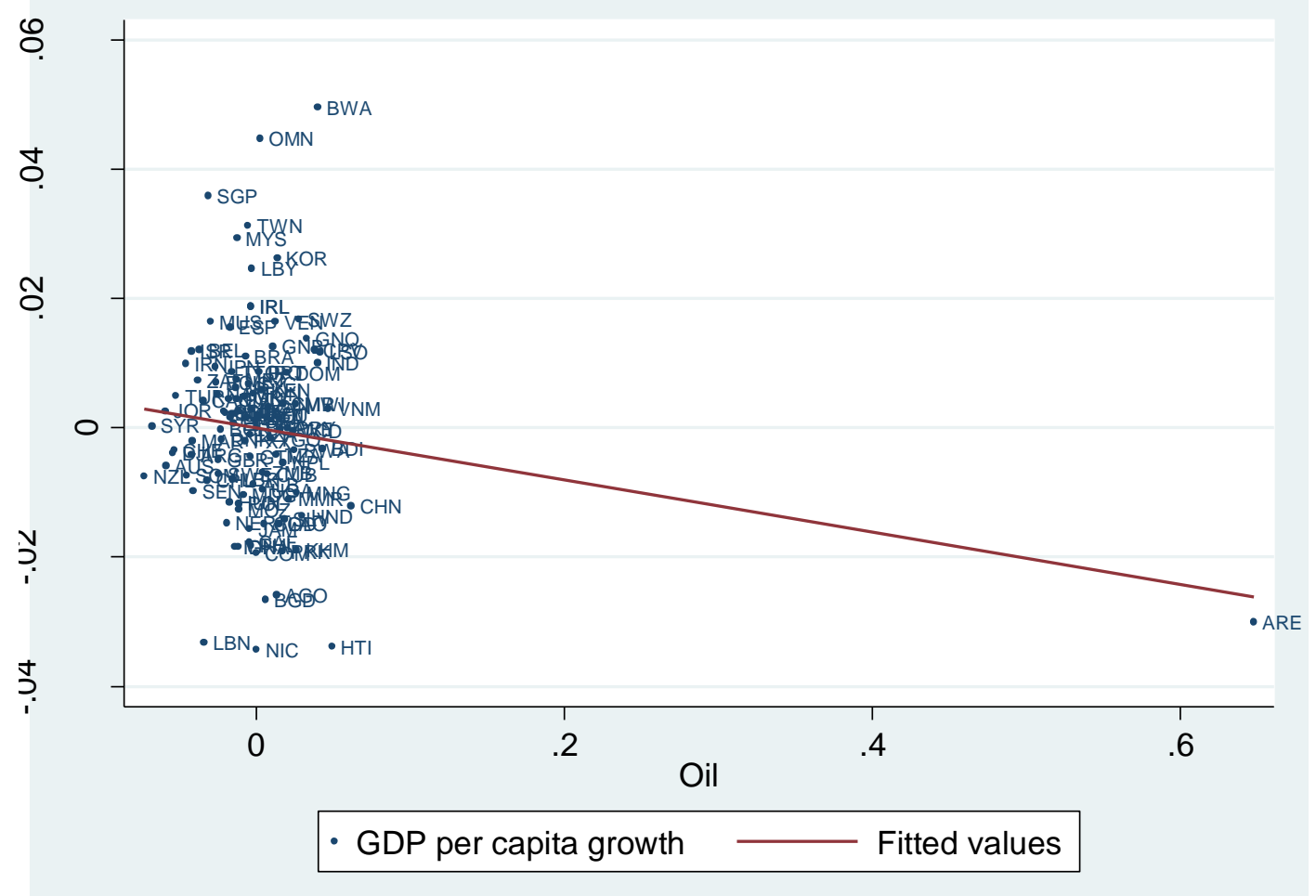

Figure A1

Conditional Correlation between GDP per capita Growth and Oil Endowment (UAE included) 


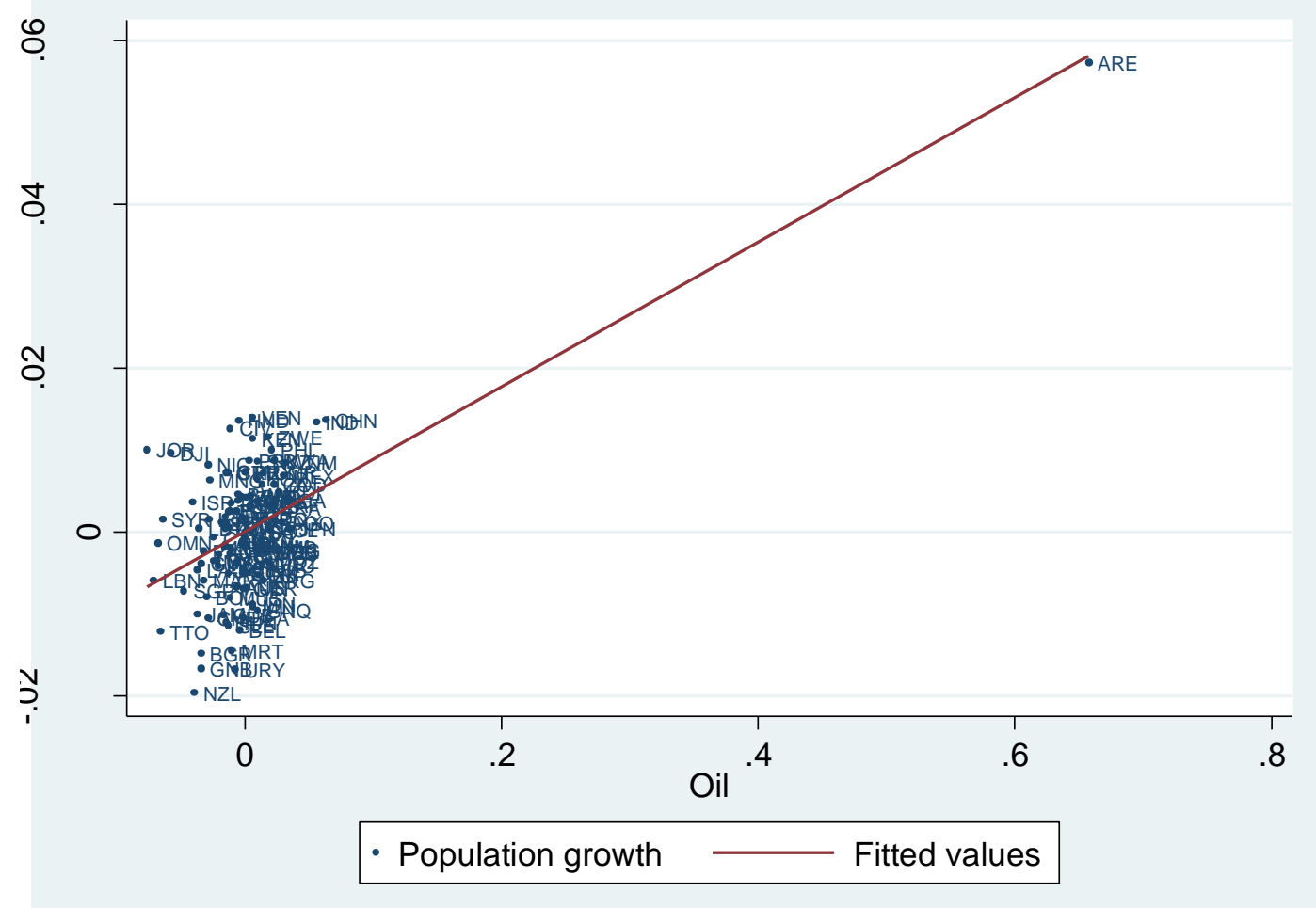

Figure A2

Conditional Correlation between Population Growth and Oil Endowment (UAE included) 